\title{
The effects of foundation size on the seismic performance of buildings considering the soil-foundation-structure interaction
}

\author{
Quoc Van Nguyen ${ }^{1 a}$, Behzad Fatahi ${ }^{* 1}$ and Aslan S. Hokmabadi ${ }^{2 b}$ \\ ${ }^{1}$ School of Civil and Environmental Engineering, University of Technology Sydney (UTS), Sydney, Australia \\ ${ }^{2}$ Ove Arup \& Partners, Hong Kong
}

(Received September 25, 2015, Revised March 27, 2016, Accepted March 30, 2016)

\begin{abstract}
Shallow footings are one of the most common types of foundations used to support mid-rise buildings in high risk seismic zones. Recent findings have revealed that the dynamic interaction between the soil, foundation, and the superstructure can influence the seismic response of the building during earthquakes. Accordingly, the properties of a foundation can alter the dynamic characteristics (natural frequency and damping) of the soil-foundation-structure system. In this paper the influence that shallow foundations have on the seismic response of a mid-rise moment resisting building is investigated. For this purpose, a fifteen storey moment resisting frame sitting on shallow footings with different sizes was simulated numerically using ABAQUS software. By adopting a direct calculation method, the numerical model can perform a fully nonlinear time history dynamic analysis to realistically simulate the dynamic behaviour of soil, foundation, and structure under seismic excitations. This three-dimensional numerical model accounts for the nonlinear behaviour of the soil medium and structural elements. Infinite boundary conditions were assigned to the numerical model to simulate free field boundaries, and appropriate contact elements capable of modelling sliding and separation between the foundation and soil elements are also considered. The influence of foundation size on the natural frequency of the system and structural response spectrum was also studied. The numerical results for cases of soil-foundation-structure systems with different sized foundations and fixed base conditions (excluding soil-foundation-structure interaction) in terms of lateral deformations, inter-storey drifts, rocking, and shear force distribution of the structure were then compared. Due to natural period lengthening, there was a significant reduction in the base shears when the size of the foundation was reduced. It was concluded that the size of a shallow foundation influences the dynamic characteristics and the seismic response of the building due to interaction between the soil, foundation, and structure, and therefore design engineer should carefully consider these parameters in order to ensure a safe and cost effective seismic design.
\end{abstract}

Keywords: seismic soil-foundation-structure interaction; shallow foundation; footing; foundation size; ABAQUS

\section{Introduction}

*Corresponding author, Senior Lecturer, E-mail: Behzad.fatahi@uts.edu.au

${ }^{a}$ Ph.D. Candidate, E-mail: Quoc.V.Nguyen-1@ student.uts.edu.au

${ }^{\mathrm{b}}$ Geotechnical Engineer, E-mail: aslan.s-hokmabadi@arup.com 
The seismic motions experienced by the foundations of a building founded on rocks are similar to the motions that occur in the same point before the structure is built. Therefore, in these cases the seismic response of the building can be calculated by considering a fixed-base assumption subjected to these specified seismic motions. However, where a building is founded on a soft deposit, two main modifications should be applied, as discussed by Wolf (1998); first, free field motion at the site without the superstructure is strongly affected; second, a superstructure built on soft soil alters the dynamic characteristics of the system, unlike the fixed-base assumption. According to Veletsos and Meek (1974), compared to a fixed-base system, the soil-foundationstructure interaction (SFSI) has two basic effects on the structural response: (i) the soil-structure system has an increased number of degrees of freedom and thus modified dynamic characteristics, and (ii) a significant part of the vibration energy of the soil-structure system may be dissipated by radiating waves emanating from the vibrating foundation-structure system back into the soil, or by hysteretic material damping in the soil. Either way this means that a soil-structure system has a longer natural period of vibration than its fixed-base counterpart.

Two key mechanisms are generally involved during a seismic soil-foundation-structure interaction: kinematic interaction and inertial interaction. Kinematic interaction occurs because stiff foundation elements in the soil cause the foundation motion to deviate from the free field ground motion. Kinematic interaction could also be due to ground motion incoherence, foundation embedment effects, and wave scattering or inclination (Stewart et al. 1999). Inertial interaction results from the inertia developed in the structure as its own vibration produces base shear, moment, and torsional excitation. These loads in turn cause displacements and the foundation to rotate relative to the free field condition (Kramer and Stewart 2004). Fundamentally, the size of a foundation can influence the kinematic and inertial interactions mainly by altering the mass and stiffness of the soil foundation system, as shown in Fig. 1, which in turn influences the seismic response of the superstructure.

Referring to Fig. 1, the inertial forces generated in the superstructure can cause rocking during strong earthquake excitations. This creates compression on one side of the foundation and tension on the other side, which in turn results in settlement on one side and possible uplift on the other side of the foundation. Ma et al. (2009) showed that rocking may be the most critical mode of vibration for a foundation because the very low hysteretic (material) damping will lead to high

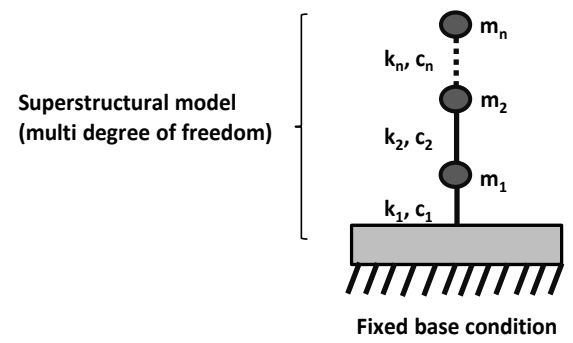

(a)

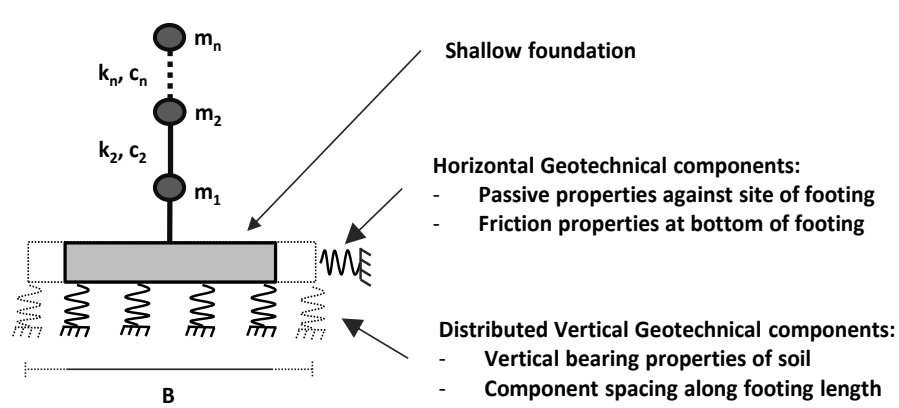

(b)

Fig. 1 Schematic modelling of the multi degree freedom structure (a) under fixed based condition excluding soil-structure interaction and (b) supported by shallow foundations considering dynamic soilfoundation-structure interaction 
motion amplitude when the excitation frequencies are close to the resonance state. Shallow foundations with varying sizes experience different amounts of rocking under a particular earthquake excitation and it is the rocking component that amplifies the lateral displacement of the superstructure and may influence its total stability. Despite this, a significant amount of earthquake energy may be dissipated due to rocking-dissipation which actually directs less shear forces to the superstructure. Gazetas and Mylonakis (1998) pointed out that in reality, the supporting soil medium allows some movements due to its natural flexibility, and this may reduce the overall stiffness of the structural system and hence, may increase the natural periods in the system. The influence that this partial fixity of the structures has at the foundation level due to soil flexibility, which is very dependent on the foundation size, in turn alters the response. Therefore, understanding the influence that a shallow foundation size has on the seismic response of buildings during earthquake excitations with respect to the soil-foundation-structure interaction can help design engineers select foundations that are the proper size for the structures and thus deliver a cost effective and safe design.

The procedures regulated in codes such as ATC-40 (1996), BSSC (2009), and ASCE7-10 (2010) do not account for the influence of foundation size, while a simplified method that represents subsoil by a series of springs and dashpots (impedance functions), and the superstructure as a simple degree of freedom oscillator, has been adopted in the regulated codes. Moreover, a linear equivalent for the subsoil has also been adopted in these codes without directly capturing any soil non-linearity that depends on the input motion and level of induced shear strain, particularly where the stiffness and damping are assumed to be constant during the solution process.

Several researchers (e.g., Sbartai 2015, Sameti and Ghannad 2014, Chen 2015) studied the seismic soil-foundation-structure interaction phenomena and its influence on the seismic response of buildings by adopting the Winkler (substructure) methods and the numerical methods. Adopting advanced numerical models has a number of advantages over the Winkler methods, especially their ability to conduct time history analyses while considering effects such as the nonlinear stress-strain behaviour of the soil and the superstructure, material and radiation damping, advance boundary conditions, and interface elements (Tabatabaiefar et al. 2014a, Hokmabadi and Fatahi 2015, Hokmabadi et al. 2014, Tabatabaiefar and Fatahi 2014). Another advantage of using numerical methods is their ability to perform the analysis in a fully-coupled manner without resorting to independent calculations of site or superstructure response (Meymand 1998). Consequently, numerical modelling predictions can capture the different parameters involved in soil-foundation-structure interaction (SFSI) that are closer to reality (e.g., Dutta and Roy 2002, Tabatabaiefar et al. 2013, Fatahi et al. 2014), which is why they were used in this study.

The aim of this study was to investigate the influence of shallow foundation size on the seismic response of a regular mid-rise moment resisting building frame during earthquake excitations. To achieve this goal, a numerical simulation of a soil-foundation-structure system was carried out in ABAQUS software (version 6.14) as a fully coupled nonlinear time history analysis. The effects of foundation size on the natural frequencies of the system as well as the response spectrum and structural performance are investigated. The results of this study can help design engineers assess the influence that foundation size has on the seismic performance of buildings sitting on soft soil, while aiming to achieve an optimised design.

\section{Characteristics of the soil-foundation-structure system}




\subsection{Characteristics of the adopted moment resisting building frame}

In this study, a fifteen storey concrete moment resisting building frame, $45 \mathrm{~m}$ high and $12 \mathrm{~m}$ wide, consisting of three spans in each direction, was selected. This building frame represents a conventional mid-rise moment resisting buildings. The structural sections were specified after conducting a routine design procedure regulated in the relevant building codes (AS3600 2009, AS1170.4, 2007). SAP2000 V 14 (CSI 2010) software was utilised for the structural analysis and design of the cross sections of beams and columns. Gravity loads, including the permanent (dead) and imposed (live) actions were determined and applied to the structural model in accordance with AS/NZS1170.1-2002 (Permanent, imposed and other actions). The values of permanent action (dead load) and imposed action (live load) were determined as uniformly distributed loads over the floors according to AS/NZS1170.1-2002, while considering the spacing of the frames as being 4 metres (Permanent Action $G=6 \mathrm{kPa}$ and Imposed Action $Q=2 \mathrm{kPa}$ ). Then, a nonlinear time-history dynamic analysis under the influence of the four earthquake ground motions shown in Fig. 9 and Table 4 was carried out. In this dynamic analysis the geometric nonlinearity and P-Delta effects were considered according to AS3600 (2009). Moreover, cracked sections for the reinforced concrete sections were considered by multiplying the coefficients of the cracked sections by the stiffness values of the structural members (EI) according to ACI318-08 (2008). Based on this standard, the coefficients of the cracked section were 0.25 and 0.7 for slabs and columns, respectively.

After finalising the dynamic analyses, concrete sections of the model were designed according to AS3600-2009 (Australian Standard for Concrete Structures). Various load combinations were considered while designing the concrete structural members subjected to Permanent $(G)$, Imposed $(Q)$, and Earthquake $(E u)$ actions according to AS/NZS1170.0-2002 (Australian Standard for structural design actions). Fig. 2 shows the structural sections which represent the structural norms and construction practices of conventional buildings in mega cities, and which were specifically used to investigate how foundation size influences the seismic response of buildings. The fundamental frequency of the adopted building was $0.830 \mathrm{~Hz}$ and its total mass was 1683 tonnes. It should be noted that the research team had previously conducted comprehensive shake table tests on a scaled structure similar to the adopted structure in this study and measurements and trends are in line with the reported numerical predictions (Tabatabaiefar et al. 2014b).

\subsection{Characteristics of the soil and shallow foundations}

The fifteen storey superstructure used in this study sits on $30 \mathrm{~m}$ deep soft soil that is categorised as Class $E_{e}$ according to the Australian standard (AS1170.4 2007), and which is defined as a site with more than $10 \mathrm{~m}$ depth of soil with a shear wave velocity of $150 \mathrm{~m} / \mathrm{s}$ or less. In this study, the sub-soil is a soft clayey soil with a density of $1470 \mathrm{~kg} / \mathrm{m}^{3}$, a shear wave velocity of $150 \mathrm{~m} / \mathrm{s}$, and an-undrained shear strength of $50 \mathrm{kPa}$. The properties of this subsoil were extracted from actual in-situ and laboratory tests (Rahvar 2006), so these parameters have merit over the assumed parameters which may not be completely conforming to reality. It was assumed that the water table was below the level of the bedrock.

The shallow square foundations (footings) were designed to support the structure against static and dynamic loads, and followed routine engineering design procedures (Bowles 2001, Poulos and Davis 1980, AS2149 2009, Nguyen et al. 2013), to satisfy the requirement for bearing capacity and maximum settlement. 


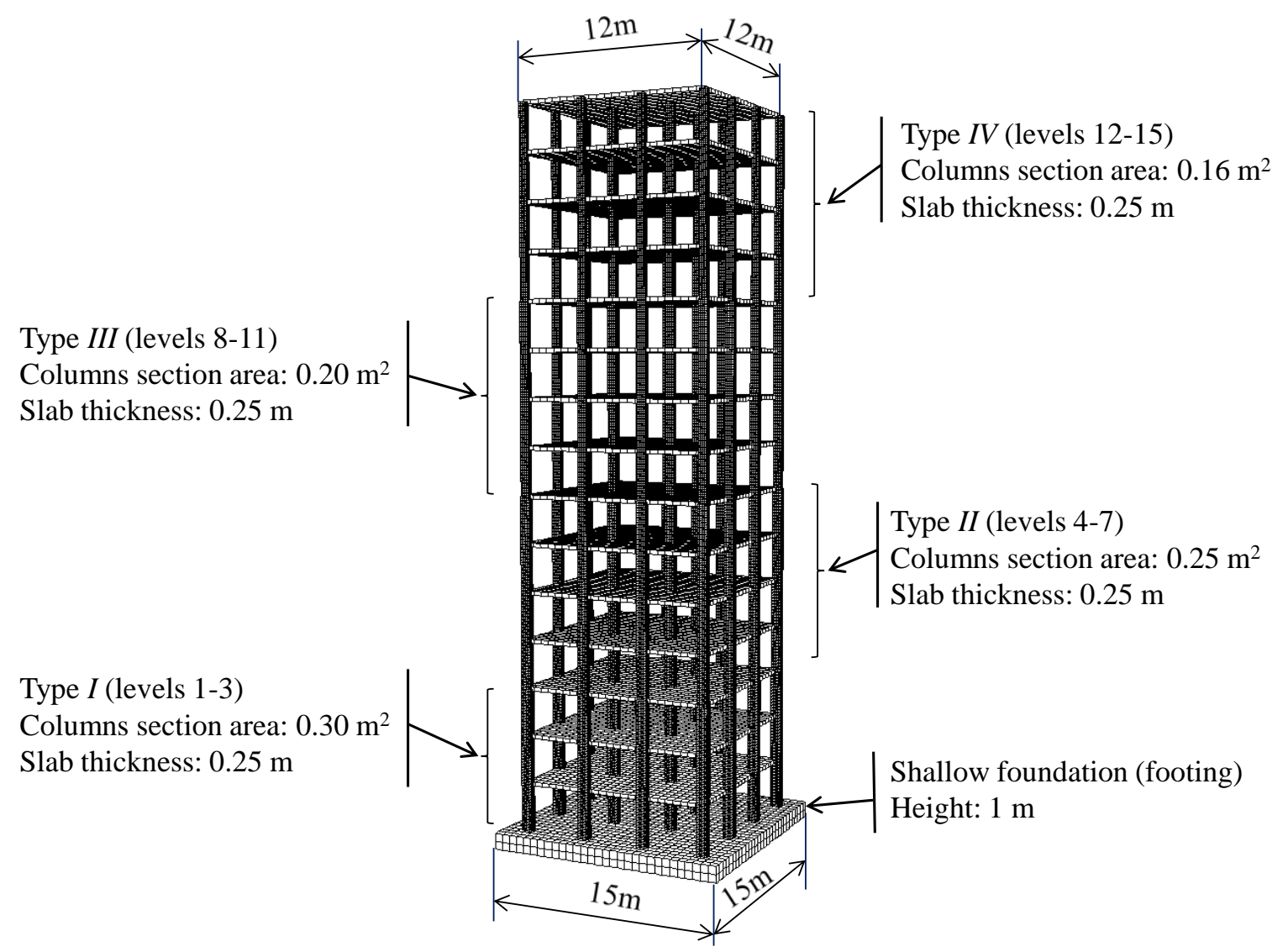

Fig. 2 Designed sections of fifteen storey moment resisting building adopted in the numerical model

All the shallow foundations were $1 \mathrm{~m}$ thick and were made from reinforced concrete. Shallow foundations with various sizes have been adapted to investigation the effect of foundation size on the seismic response of building considering the soil-foundation-structure interaction. These foundations had seven different sizes, including: 1.1B, 1.2B, 1.3B, 1.4B, 1.5B, 1.7B and 2.0B, where $B$ is the width of the building $(=12 \mathrm{~m})$. All these foundation sizes were acceptable from an engineer's perspective and satisfied the requirements for bearing capacity and maximum settlement, although the safety factor of the smaller foundations was less than the large ones. Moreover, although the $1.7 \mathrm{~B}$ and $2.0 \mathrm{~B}$ foundations are not common in practice, a wider range of foundation sizes was considered in this study to better understand how foundation size affects the seismic response of a building during strong earthquakes. The seismic response of these foundation sizes are compared and discussed in the following sections via a 3D finite element numerical simulation.

\section{Numerical model}

The governing equations of motion for the structure incorporating foundation interaction and the 
method of solving these equations are relatively complex because unlike ordinary dynamic time history equations of motions, these dynamic equations of motion of the soil and structure system are a combination of different vectors and matrices of the soil and the structure. This combination makes the equation too mathematically sophisticated to be solved by conventional methods, so a simplified approach to the substructure where the SFSI problem was decomposed into (a) an evaluation of a Foundation Input Motion (FIM), (b) a determination of the impedance function, and (c) a dynamic analysis of the structure supported on a compliant base but represented by the impedance function and subjected to a base excitation consisting of the FIM, has been used extensively by practicing engineers and researchers. However, according to Wolf (1998), since this method is based on the principle of superposition, any predictions would only be accurate for linear soil and structural behaviours, while approximations of soil nonlinearity by means of iterative wave propagation analyses, would allow the superposition to be applied to moderately-nonlinear systems.

The direct method of analysis where the entire soil-structure system is modelled in a single step (no need to decompose the system to sub-structure and super-structure), can result in the most realistic modelling and analysis, but more advanced computer programs are required in this method. Since assumptions of superposition are not required, true and accurate nonlinear analyses are possible in this case (Borja et al. 1994). Therefore, the direct method, which is better at modelling the complex nature of the soil-foundation-structure interaction in dynamic analysis, was used in this study. ABAQUS v 6.14 finite element analysis software was used in this study for the numerical simulation of the soil-foundation-structure systems. This software package can simulate complex problems that require large computational memories using a direct method of analysis. A number of researchers (e.g., Matinmanesh and Asheghabadi 2011, Chu and Truman 2004, Koskinen 2005, Moss et al. 2010) used ABAQUS to study soil-structure interaction problems. The numerical modelling procedure used to simulate structural elements and soil models, as well as the contact surfaces and boundary conditions, is explained below.

\subsection{Structural model}

Beam and shell elements were used to simulate the columns and floor slabs of the superstructure in this numerical model. The characteristics of the columns and floor slabs are presented in Tables 1 and 2, respectively, while taking the cracked sections into consideration in accordance with (ACI318-08, 2008). The structural elements were modelled using an elasticviscoelastic constitutive model while considering the Rayleigh damping described below.

According to Ryan and Polanco (2008), the damping matrix in Rayleigh damping is a linear combination of mass-proportional and stiffness-proportional terms

$$
[C]=\alpha[M]+\beta[K]
$$

Table 1 Characteristics of designed reinforced concrete column sections adopted in 3D finite element modelling

\begin{tabular}{cccccc}
\hline \hline Section Type & $I_{x}\left(\mathrm{~m}^{4}\right)$ & $I_{y}\left(\mathrm{~m}^{4}\right)$ & Area $\left(\mathrm{m}^{2}\right)$ & $E(\mathrm{kPa})$ & $v$ \\
\hline Type I (Levels 1 - 3) & $5.33 \mathrm{E}-3$ & $10.87 \mathrm{E}-3$ & 0.302 & $3.01 \mathrm{E} 8$ & 0.2 \\
Type II (Levels 4 - 7) & $3.64 \mathrm{E}-3$ & $7.45 \mathrm{E}-3$ & 0.250 & $3.01 \mathrm{E} 8$ & 0.2 \\
Type III (Levels 8 - 11) & $2.40 \mathrm{E}-3$ & $4.89 \mathrm{E}-3$ & 0.203 & $3.01 \mathrm{E} 8$ & 0.2 \\
Type IV (Levels 12 - 15) & $1.50 \mathrm{E}-3$ & $3.05 \mathrm{E}-3$ & 0.160 & $3.01 \mathrm{E} 8$ & 0.2 \\
\hline
\end{tabular}


Table 2 Characteristics of the designed reinforced concrete floor slabs and foundations adopted in 3D numerical model

\begin{tabular}{cccc}
\hline \hline Properties & Denote & Unit & Value \\
\hline Floor slab thickness & $h_{s}$ & $m$ & 0.25 \\
Foundation thickness & $h_{f}$ & $m$ & 1.0 \\
Density & $\rho$ & $\mathrm{kg} / \mathrm{m} 3$ & 2400 \\
Young's modulus & $E$ & $\mathrm{kPa}$ & $3.01 \mathrm{E} 8$ \\
Poisson's ratio & $v$ & - & 0.2 \\
\hline
\end{tabular}

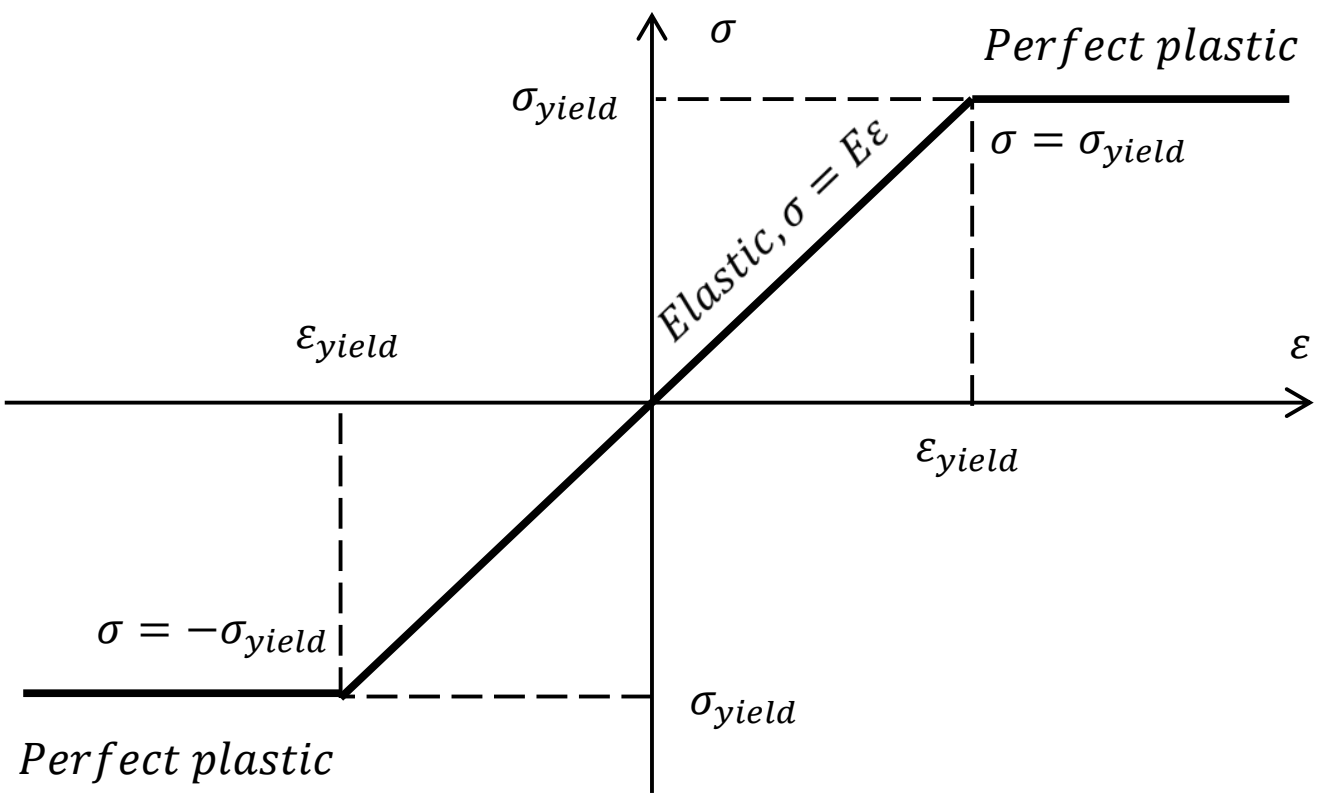

Fig. 3 Elastic-perfectly plastic behaviour of structural elements

where $[C],[M]$, and $[K]$ are the damping, mass, and stiffness matrices, respectively, $\alpha$ and $\beta$ are the model coefficients used to specify the model damping ratio in two modes. By assuming the same damping ratio $(\xi)$ for two modes with frequencies $f_{i}$ and $f_{j}$, the model coefficients $\alpha$ and $\beta$ can be obtained as follows

$$
\alpha=\xi \frac{2 f_{i} f_{j}}{f_{i}+f_{j}} ; \beta=\xi \frac{2}{f_{i}+f_{j}}
$$

Moreover, the damping ratio in any vibration mode with frequency $f_{n}$ for given model coefficients ( $\alpha$ and $\beta$ ) can be computed by using the following equation (Chopra 2007)

$$
\xi_{n}=\frac{\alpha}{2 f_{n}}+\frac{\beta f_{n}}{2}
$$

In this study, a structural damping ratio $(\xi)$ of $5 \%$ together with model coefficients of $\alpha=0.3996$ and $\beta=0.0049$, calculated based on the first and second mode frequencies of the structure (see Table 5), was used to simulate structural damping in the dynamic analysis. 
Furthermore, the inelastic behaviour of structural elements was simulated using elasticperfectly plastic material behaviour by specifying the yield stress. The elastic-perfectly plastic material model used in this study for inelastic analysis and design assumed that structural elements behave elastically until they reach the defined yield stress. The element that reaches the yield stress can continue to deform without inducing additional stresses. According to Shing and Tanabe (2001), the yield stress of concrete material $\left(\sigma_{y}\right)$ was assumed to be equal to the compressive strength of concrete $\left(f^{\prime} c\right)$. Fig. 3 illustrates the elastic-perfectly plastic behaviour of the structural elements used in this study. For the structural concrete utilised in this design and analysis, the specified compressive strength $\left(f^{\prime}{ }_{c}\right)$ and mass density $(\rho)$ were assumed to be $32 \mathrm{MPa}$ and 2400 $\mathrm{kg} / \mathrm{m}^{3}$, respectively. The modulus of elasticity of concrete $(E)$ was calculated according to clause 3.1.2.a of the Australian Standard for Concrete Structures (AS3600 2009).

\subsection{Soil model}

The nonlinearity of soil during an earthquake plays an important role in the dynamic response of soil-structure systems. The equivalent linear method has been in use for many years to calculate the wave propagation (and response spectra) in soil and rock at sites subjected to seismic excitations. In an equivalent-linear method adopted in this study, a linear analysis is carried out with some assumed initial values for the damping ratio and shear modulus in various regions of the model. Then the maximum cyclic shear strain is recorded for each element and used to determine the new values for damping and modulus by referring to the backbone curves relating the damping ratio and secant modulus to the amplitude of shear strain. Some empirical scaling factors are usually utilised when relating these strains to the model strains, and then these new values for the damping ratio and shear modulus are used in the next stage of the numerical analysis. The whole process is repeated several times, until there is no further change in the properties and the structural response. At this stage, "strain compatible" values of damping and modulus are recorded, and the simulation using these values is deemed to be the best possible prediction of the real behaviour. As described by Seed and Idriss (1969), the equivalent-linear method uses linear properties for each element because they remain constant under the influence of seismic excitations; those values are estimated from the mean level of dynamic motion, as explained before, but since trial and error utilising nonlinear backbone curves to find the "strain compatible" values of damping and modulus is used, soil nonlinearity was captured by this method.

Hysteresis of typical soils subjected to the cyclic loading can be described using two important characteristics of the hysteresis loop shape: inclination and breath. As explained by Kramer (1996), the inclination of the loop represents stiffness of the soil, which can be described at any point during the loading process by the tangent shear modulus. The breath of the hysteresis loop, which is related to the area of one hysteresis loop, represents the energy dissipation and can be described by the damping ratio. The parameters $G_{\text {sec }}$ and $\xi$ were used to describe the cyclic behaviour of soil in the equivalent linear analysis and are often referred to as the soil equivalent linear parameters (Kramer 1996)

$$
\begin{gathered}
G_{s e c}=\tau_{c} / \gamma_{c} \\
\xi=W_{d} /\left(4 \pi \times W_{s}\right)
\end{gathered}
$$

Vucetic and Dobry (1991) conducted a comprehensive study on the number of cyclic test results available and concluded that the soil Plasticity Index $(P I)$ controls the location of the backbone curves for a wide variety of cohesive soils. The numerical model developed in this study 

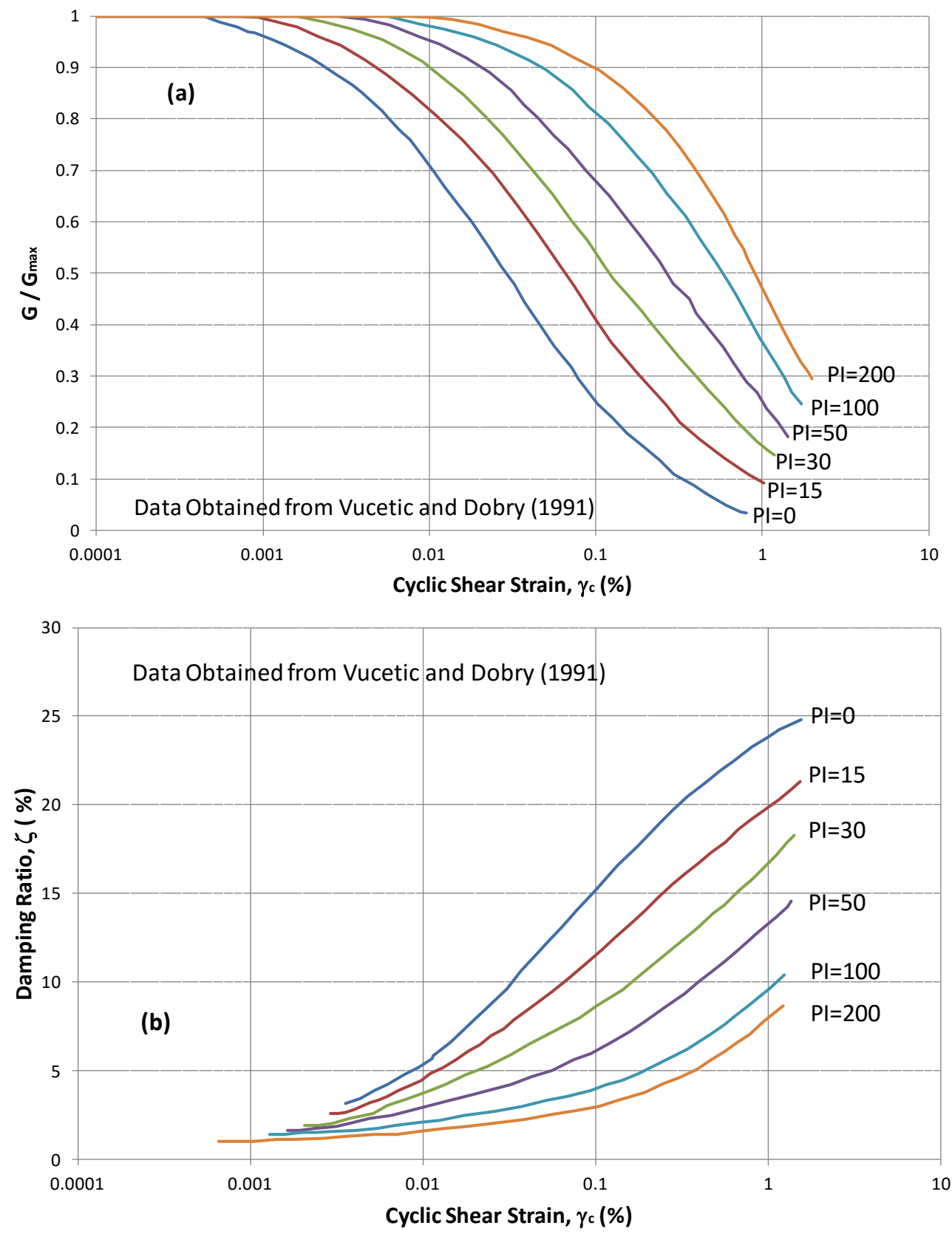

Fig. 4 (a) Backbone curves relating (a) shear stiffness and (b) damping ratio to cyclic shear strain for cohesive soils

adopts the ready-to-use charts (Figs. 4(a), (b)) provided by Vucetic and Dobry (1991) to estimate the modulus degradation and damping ratio of cohesive soils in dynamic analysis. These charts provide a design tool for practicing engineers because the $P I$ of soil is readily available. It should be noted that as the plasticity index increases, $G_{s e c} / G_{\max }$ increases while the damping ratio 
Table 3 Adopted soil parameters in 3D finite element model for the soil-foundation-structure system

\begin{tabular}{|c|c|c|c|c|c|}
\hline & Soil Properties & Denote & Unit & Value & Reference \\
\hline & Mass density & $\rho$ & $\mathrm{kg} / \mathrm{m}^{3}$ & 1470 & \multirow{4}{*}{ Rahvar (2006) } \\
\hline & Shear Wave Velocity & $V_{s}$ & $\mathrm{~m} / \mathrm{s}$ & 150 & \\
\hline & Poisson's ratio & $v$ & - & 0.4 & \\
\hline & Plasticity Index & $P I$ & - & $15 \%$ & \\
\hline \multirow{5}{*}{$\begin{array}{l}\text { Mass } \\
\text { damping } \\
\text { factor }\end{array}$} & Northridge & & - & 0.937 & \multirow{9}{*}{$\begin{array}{c}\text { Vecetic and } \\
\text { Dobry (1991); } \\
\text { (Park and } \\
\text { Hashash 2004) }\end{array}$} \\
\hline & $\begin{array}{c}\left(\gamma_{\max }=0.26 \%, G / G_{\max }=0.25, \xi=15.9 \%\right) \\
\text { Kobe }\end{array}$ & & & & \\
\hline & $\left(\gamma_{\max }=0.20 \%, G / G_{\max }=0.3, \xi=14.6 \%\right)$ & & - & 0.942 & \\
\hline & $\begin{array}{c}\text { Hachinohe } \\
\left(\gamma_{\max }=0.03 \%, G / G_{\operatorname{ma}}=0.65, \xi=7.2 \%\right)\end{array}$ & $\alpha$ & - & 0.141 & \\
\hline & $\begin{array}{c}\text { El-Centro } \\
\left(\gamma_{\max }=0.13 \%, G / G_{\max }=0.35, \xi=12.8 \%\right)\end{array}$ & & - & 0.893 & \\
\hline \multirow{4}{*}{$\begin{array}{l}\text { Stiffness } \\
\text { damping } \\
\text { factor }\end{array}$} & $\begin{array}{c}\text { Northridge } \\
\left(\gamma_{\max }=0.26 \%, G / G_{\max }=0.25, \xi=15.9 \%\right)\end{array}$ & \multirow{4}{*}{$\beta$} & - & 0.020 & \\
\hline & $\begin{array}{c}\text { Kobe } \\
\left(\gamma_{\max }=0.20 \%, G / G_{\max }=0.3, \xi=14.6 \%\right)\end{array}$ & & - & 0.017 & \\
\hline & $\begin{array}{c}\text { Hachinohe } \\
\left(\gamma_{\max }=0.03 \%, G / G_{\max }=0.65, \xi=7.2 \%\right)\end{array}$ & & - & 0.019 & \\
\hline & $\begin{array}{c}\text { El-Centro } \\
\left(\gamma_{\max }=0.13 \%, G / G_{\max }=0.35, \xi=12.8 \%\right)\end{array}$ & & - & 0.014 & \\
\hline
\end{tabular}

decreases.

Since each earthquake record induces different levels of shear strain in the soil deposit, the values for soil damping and modulus would be different for each earthquake when the nonlinearity of the soil is considered. Table 3 summarises the "strain compatible" parameters of soil used in this study when developing the 3D numerical model for four earthquakes. As mentioned earlier, since the properties of the subsoil were extracted from actual in-situ and laboratory tests (Rahvar 2006), they have merit over those assumed parameters which may not completely conform to reality.

Soil damping, which simulates the absorption of energy by particles of soil and their interaction during wave propagation, reduces the wave amplitude and has a significant influence on how the superstructure performs. Das (1983) mentioned that the most commonly used mechanism for representing energy dissipation is viscous damping which assumes that the dissipative forces are a function of particle velocity. In this study the nonlinear variations of energy losses in the soil during an earthquake were simulated using the Rayleigh damping formulation. Park and Hashash (2004) investigated whether the Rayleigh damping formulation could perform a nonlinear dynamic analysis of soil deposits and concluded that it can provide acceptable results for many applications as long as the parameters for the deposit of soil are selected accurately.

Considering the frequency dependent nature of these Rayleigh damping formulations, the frequencies/modes selected to define the damping function govern the accuracy of the time domain solution, but care should be exercised when selecting frequencies to avoid any negative damping in the resulting frequency dependent damping (Park and Hashash 2004). The two significant frequencies can be chosen in part to cover the range of frequencies where there is significant 


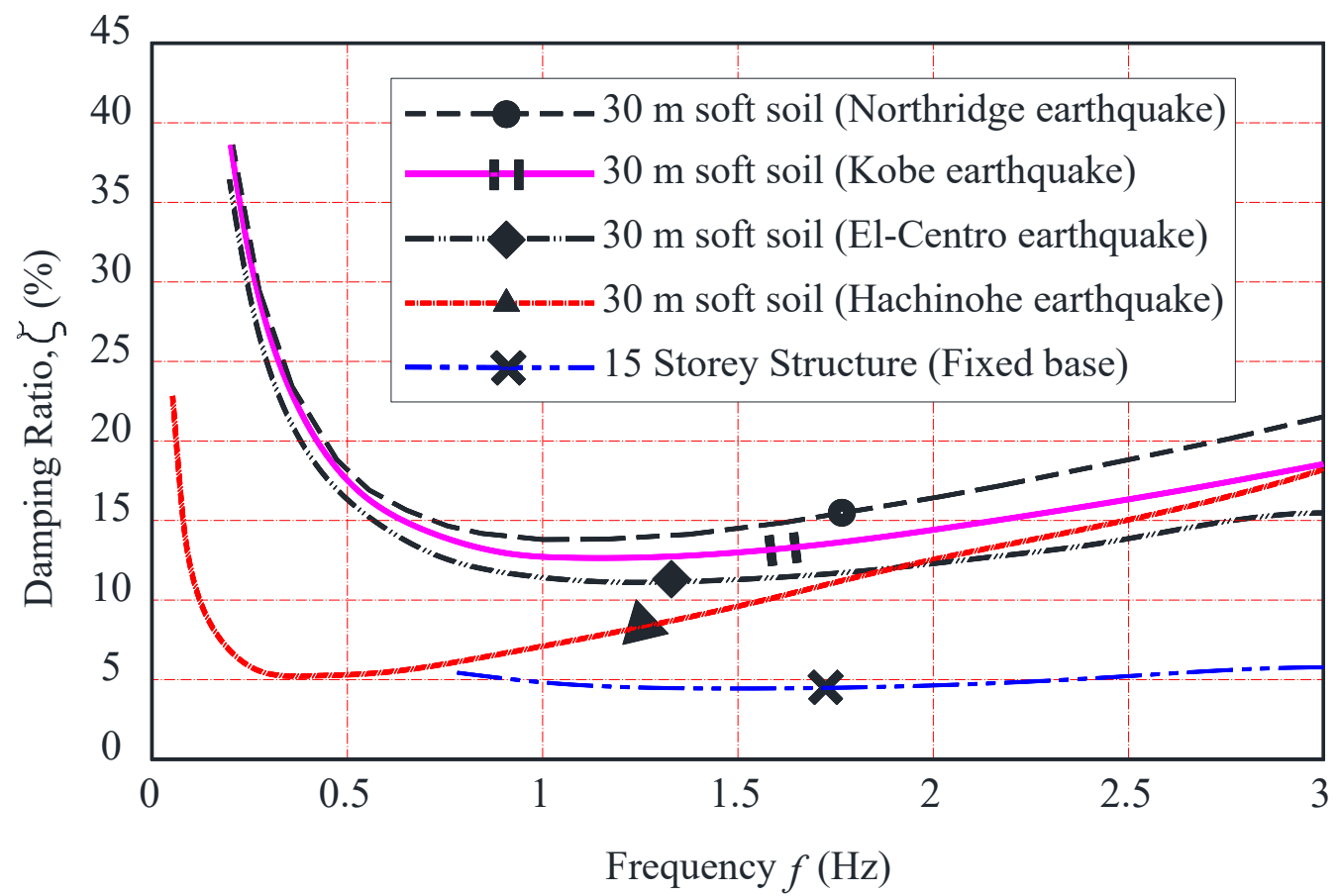

Fig. 5 Adopted damping variations in this study for soft soil deposit and structure for numerical simulation of dynamic soil-foundation-structure interaction

content of input motion. Kramer (1996) presented the following equation to calculate the natural frequencies of the soil deposit

$$
f_{n}=\frac{V_{s}}{4 H}(2 n-1)
$$

where $n$ is the mode number, $f_{n}$ is the natural frequency of the corresponding mode, $V_{s}$ is the shear wave velocity of the soil deposit, and $H$ is its thickness. Referring to Fig. 5, the two significant frequencies are chosen covering the range of dominant frequencies of the ground motion. In this study, following the recommendations by Park and Hashash (2004), a set of frequencies corresponding to the "strain compatible" shear modulus values for different earthquakes are selected. The Rayleigh damping parameters used in the numerical model are summarised in Table 3 and Fig. 5.

The soil medium was modelled using C3D8R elements (three-dimensional, 8-node linear brick, reduced integration, hourglass control elements), as shown in Fig. 6(a) where, due to reduced integration, the locking phenomena does not occur, but the element tends to be not stiff enough in bending, which is not critical when modelling soil. Moreover, since the integration point is located in the middle of this element, small elements are needed to capture a stress concentration at the boundaries.

\subsection{Contact surfaces}

The contact surfaces were used to incorporate the different mechanical characteristics of the 


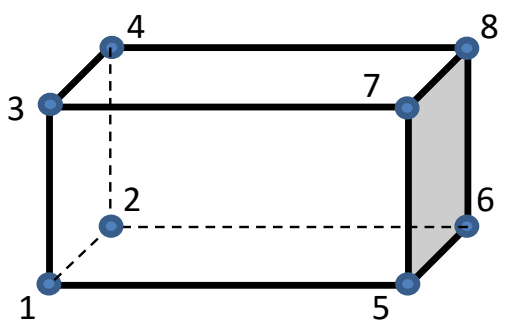

(a)

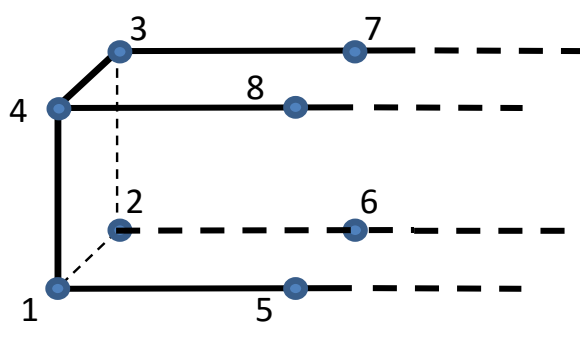

(b)

Fig. 6 Employed element types in the finite element numerical model: (a) soil elements (C3D8R); and (b) infinite elements (CIN3D8)

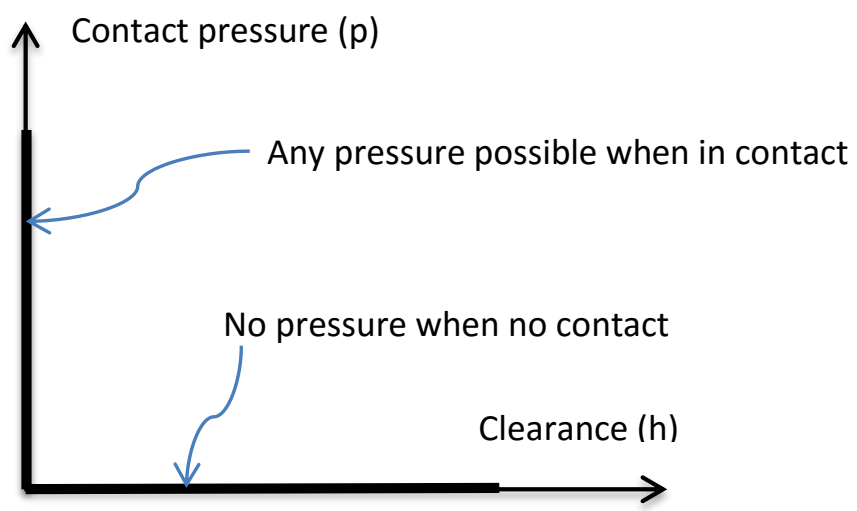

Fig. 7 Pressure - over closure relationship for 'Hard' contact to define the normal behaviour of contact surfaces in the numerical model

soil and the shallow foundation, while capturing any possible uplift and sliding of the foundation over the subsoil during shaking excitations. In ABAQUS, contact elements or surfaces can be used to model the interface between the foundation and the soil surface during shaking excitations. For the soil-foundation-structure interaction analysis in this study, surface-based contacts were defined such that the master surface is the top surface of the soil and the slave surface is the bottom surface of the foundation. Moreover, finite sliding formulation and the surface-to-surface discretisation method were utilised for the contact simulation to consider the shape of the master and slave surfaces when defining the contact constraints. In addition, the "Augmented Lagrange method" was used in conjunction with the penalty stiffness being 1000 times more than the representative underlying element stiffness as recommended by ABAQUS (2012). Lagrange multipliers are only used for the augmented Lagrange method if the penalty stiffness exceeds 1000 times the representative underlying element stiffness; otherwise, no Lagrange multipliers are used. In this numerical modelling, since the penalty stiffness ratio does not exceed 1000 , there was no need to incorporate the Lagrange multiplier.

The mechanical properties of the contact surfaces defining the tangential and normal behaviour of the contact surfaces can influence the results of the numerical simulation and should be chosen with great rigor. Normal behaviour adopts 'hard' contact in a pressure-over closure relationship, where a 'hard' contact implies that the surfaces transmit no contact pressure unless the nodes of 
the slave surface make contact with the master surface, no penetration is allowed at the location of each constraint (depending on the method used to enforce constraint, this condition will either be strictly satisfied or approximated), and there is no limit to the magnitude of contact pressure that can be transmitted when the surfaces are in contact. The 'hard' contact with pressure-over closure relationship in the method used to enforce constraint expressed using Eq. (7), is illustrated in Fig. 7. In Eq. (7), $p$ is the contact pressure and $h$ is the clearance or gap between two contacting surfaces.

$$
P \times h=0, p \geq 0 \text { and } h \geq 0
$$

A subroutine developed in the FORTRAN programming language and linked to ABAQUS was used to model the tangential behaviour of contact surfaces in the finite element model. This subroutine defines the variable required in the numerical simulation in a way that corresponds to the classical Mohr-Coulomb failure model. Since the Mohr-Coulomb failure model cannot be directly defined in the simulation, a modified version of this model (Eq. (8)) was coded in the FRIC_COEF subroutine to define the isotropic frictional coefficient between the contacting surfaces.

$$
\mu=\tau / \sigma=\tan (\varphi)+\frac{c}{\sigma}
$$

where $\mu$ is the coefficient of friction, $\tau$ is the shear strength, $\sigma$ is the normal stress, $c$ is the cohesion intercept of the failure envelope, and $\varphi$ is the slope of the failure envelope or the internal friction angle.

\subsection{Boundary conditions}

The boundary conditions in the numerical model were prescribed at the boundaries of the numerical grids. The far-field soil was represented by infinite elements to account for the energy absorbed from the unbounded soil domain while horizontal deformation was also simulated realistically (Fig. 8). The three-dimensional, 8-node linear one-way infinite brick (CIN3D8) elements were used to model the infinite elements, as shown in Fig. 6(b), but unlike the other numerical elements, these infinite elements have defined orientations. Referring to Fig. 6(b), nodes 1, 2, 3 and 4 were connected to defined finite elements (subsoil), while the other nodes (nodes 5, 6, 7 and 8) were oriented outwards from the defined finite elements.

During dynamic steps, the infinite elements introduced additional normal and shear tractions on the finite element boundary that were proportional to the normal and shear components of the velocity of the boundary. These boundary damping constants were chosen to minimise the reflection of dilatational and shear wave energy back into the finite element mesh. The infinite elements maintained the static force that was present at the end of the gravity (static) analysis stage, so there was no need to displace the boundaries for the time-history dynamic analysis stage (ABAQUS 2012).

The dynamic response of the infinite elements was based on a consideration of the plane body waves travelling orthogonally to the boundary. The governing equation of motion in the boundaries is presented in Eq. (9), and the distributed damping on the infinite boundaries of the developed numerical model in the normal and shear directions are as presented in Eq. (10)

$$
\rho \ddot{u}_{i}=G \frac{\partial^{2} u_{i}}{\partial x_{i} \partial x_{j}}+(\lambda+G) \frac{\partial^{2} u_{j}}{\partial x_{i} \partial x_{j}}
$$




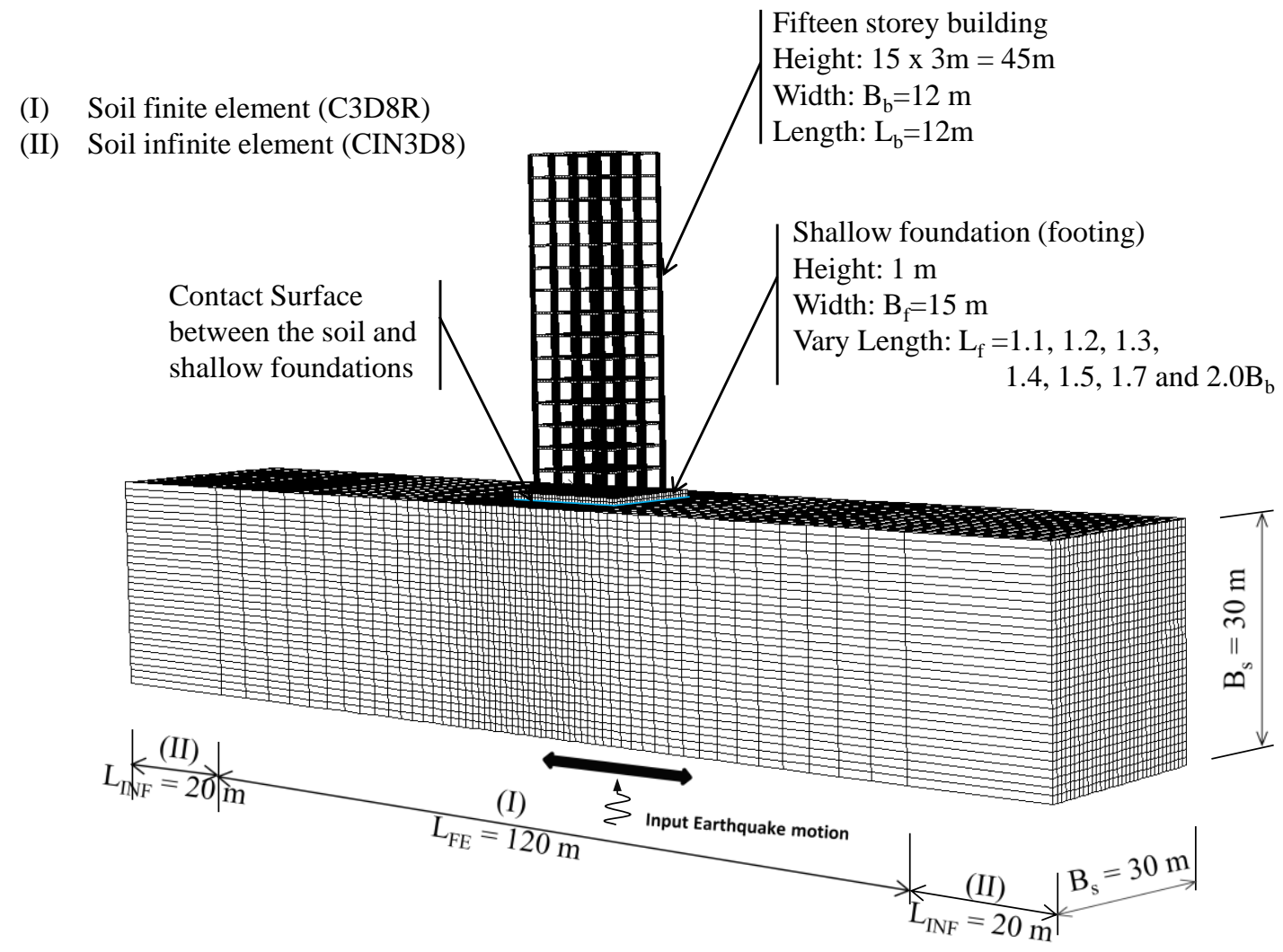

Fig. 8 Integrated soil-foundation-structure system highlighting boundary conditions, main grid, and contact surfaces utilised in the numerical simulation

$$
d_{p}=G \frac{\lambda+2 G}{c_{p}} ; d_{s}=\rho c_{s}
$$

where $\rho, G, \lambda$ are the soil properties, $c_{p}$ and $c_{s}$ are the velocities of the normal wave and shear wave, respectively, $d_{p}$ and $d_{s}$ are the distributed damping of the boundary in the normal and shear directions, respectively, $u_{j}$ is the material particle displacement, $x_{i}$ and $x_{j}$ are the positions of noted $i$ and $j$.

The values of the boundary damping were built into the infinite elements in ABAQUS. As discussed earlier, these boundaries can transmit all the normally impinging plane body waves, and even for problems that involve non-plane body waves that do not impinge on the boundary from an orthogonal direction, the defined boundaries work well (Cohen and Jennings 1983). Since the boundaries were "quiet" rather than silent (perfect transmitters of all waveforms), and because the boundaries relied on the medium adjacent to them being linear elastic, they should be placed a reasonable distance away from the region of main interest; which was carried out in this study. During the dynamic response analysis following the static gravity preload (as is common in geotechnical applications), the traction provided by the infinite elements to the boundary of the finite element mesh consisted of the constant stress obtained from the static response with the quiet boundary damping stresses added. 
Table 4 Characteristics of the adopted earthquake records

\begin{tabular}{cccccccc}
\hline \hline Earthquake & Country & Year & $\begin{array}{c}\text { PGA } \\
(\mathrm{g})\end{array}$ & $\begin{array}{c}\text { Mw } \\
(\mathrm{R})\end{array}$ & $\begin{array}{c}\text { Duration } \\
(\mathrm{s})\end{array}$ & Type & $\begin{array}{c}\text { Hypocentral } \\
\text { Distance* }(\mathrm{km})\end{array}$ \\
\hline Northridge & USA & 1994 & 0.843 & 6.7 & 30.0 & Near field & 9.2 \\
Kobe & Japan & 1995 & 0.833 & 6.8 & 56.0 & Near field & 7.4 \\
El Centro & USA & 1940 & 0.349 & 6.9 & 56.5 & Far field & 15.69 \\
Hachinohe & Japan & 1968 & 0.229 & 7.5 & 36.0 & Far field & 14.1 \\
\hline
\end{tabular}

*Obtained from (PEER 2012)

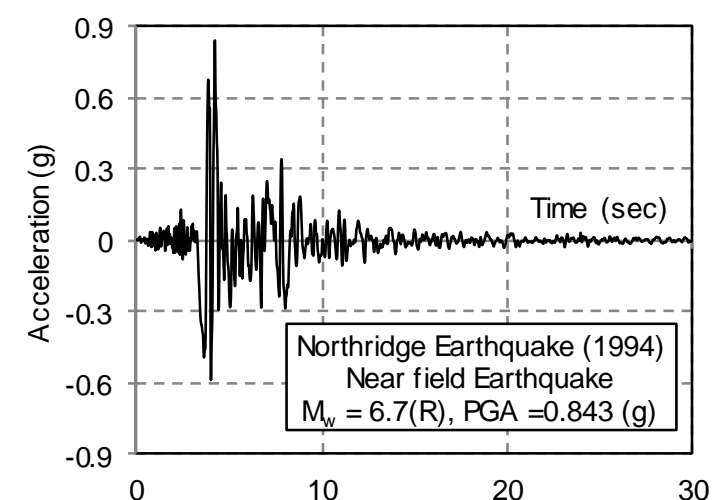

(a)

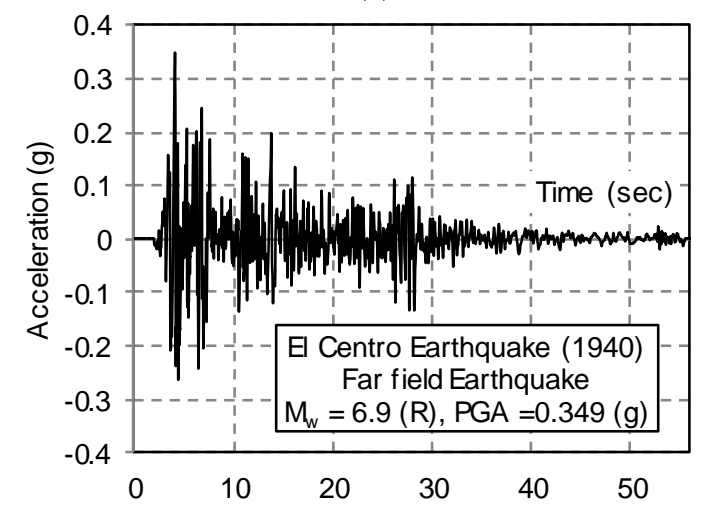

(c)

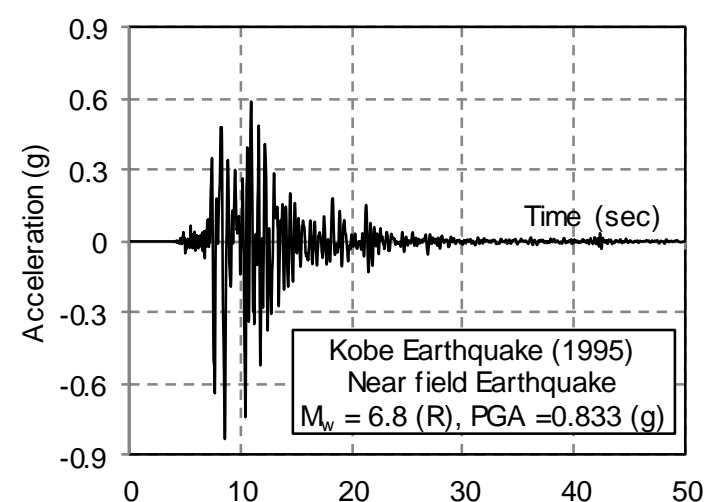

(b)

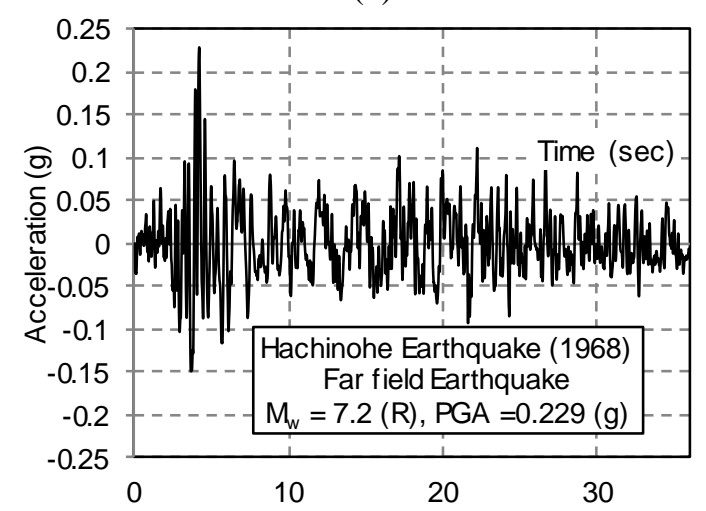

(d)

Fig. 9 Adopted earthquake records: : (a) 1994 Northridge earthquake; (b) 1995 Kobe; (c) 1940 El Centro earthquake; and (d) 1968 Hachinohe earthquake

Note that the material properties assigned to the infinite elements must match the material properties of the adjacent finite elements in the model (Table 3). Moreover, only linear behaviour can be associated with infinite elements, but since they are located in the far field, the effect of this simplified assumption on the response of the superstructure under shaking excitations is negligible.

A rigid boundary condition was used to simulate bedrock (the bottom of the soil medium grid) in the seismic soil-foundation-structure interaction analysis, as suggested by other researchers 
(Fatahi and Tabatabaiefar 2013), while the earthquake input motions were applied at the bedrock propagating upwards through the entire model.

\subsection{Input earthquake records}

Four benchmark earthquake input motions, including the 1994 Northridge, the 1995 Kobe, the 1940 El Centro, and the 1968 Hachinohe earthquakes (referring to Table 4 and Fig. 9), were imposed onto the finite element numerical model while conducting a time-history analysis. Fig. 8 shows the model components and the numerical mesh for the building supported by the shallow foundations. Note that to make the results comparable for different size foundations without being affected by the meshing variables, the same generated mesh was used for all sizes of the shallow foundations. The generated mesh shown in Fig. 8 consisted of 42123 elements and 61021 nodes. Due to the large size of the model (around 70 Giga-bytes for a single case), the fast computation facilities at the University of Technology Sydney were used to conduct this time-history analysis, and even then it took around 50 hours to run a single case under the applied earthquake excitation. The results of the 3D finite element numerical simulation are presented and discussed in the following section.

\section{Results and discussion}

At first, the fixed-base structure excluding SFSI was simulated. The responses of the fixed-base structure under the influence of four earthquake excitations were used as a comparison benchmark to investigate the influence of SFSI on structures with various shallow foundation sizes. The natural frequencies of the fixed-base structure are presented in Table 5. Fig. 10 shows the deformed shape of the structure on its natural modes.

The results of the 3D numerical model developed for the fifteen-storey building supported by shallow foundations of different sizes and the fixed-base building subjected to the 1994 Northridge, 1995 Kobe, 1940 El Centro, and 1968 Hachinohe earthquakes are summarised and compared in Figs. 11, 12, 13, and 14, respectively. To determine the lateral deflections, the movement of the foundation was subtracted from the movement of the storeys, which means that all the records are relative to the movements of the foundation on the soil surface level. This data was based on the lateral deformation of each storey when maximum deflection at the top level occurred because as Hokmabadi et al. (2012) stated, this approach gives a more reasonable pattern of structural deformations than approach where the maximum absolute deformation of the storeys, regardless of the time they occurred and were recorded.

According to Figs. 11(a), 12(a), 13(a), and 14(a), SFSI amplified the maximum lateral deflection of the superstructure during shaking excitations, as was expected. For instance, the maximum lateral deformation of the fixed-base building (excluding SFSI) under the 1994 Northridge earthquake was $395 \mathrm{~mm}$, while the same building experienced a lateral deformation of up to $590 \mathrm{~mm}$ (49\% more) when it was supported by a 1.1B shallow foundation that accounts for SFSI. Moreover, as a general trend, by increasing the size of the shallow foundation from 1.1B to $2.0 \mathrm{~B}$ the structure experiences less lateral deformation. For instance, an increase in the size of the foundation from 1.1B to $1.5 \mathrm{~B}$ resulted in up to $25 \%$ less lateral deformation under $1940 \mathrm{El}$ Centro earthquake (Fig. 13(a)). This is a considerable reduction in the lateral deformation of a structure subjected to strong earthquakes. 
Table 5 Natural frequencies of the adopt 15 storey fixed base structure

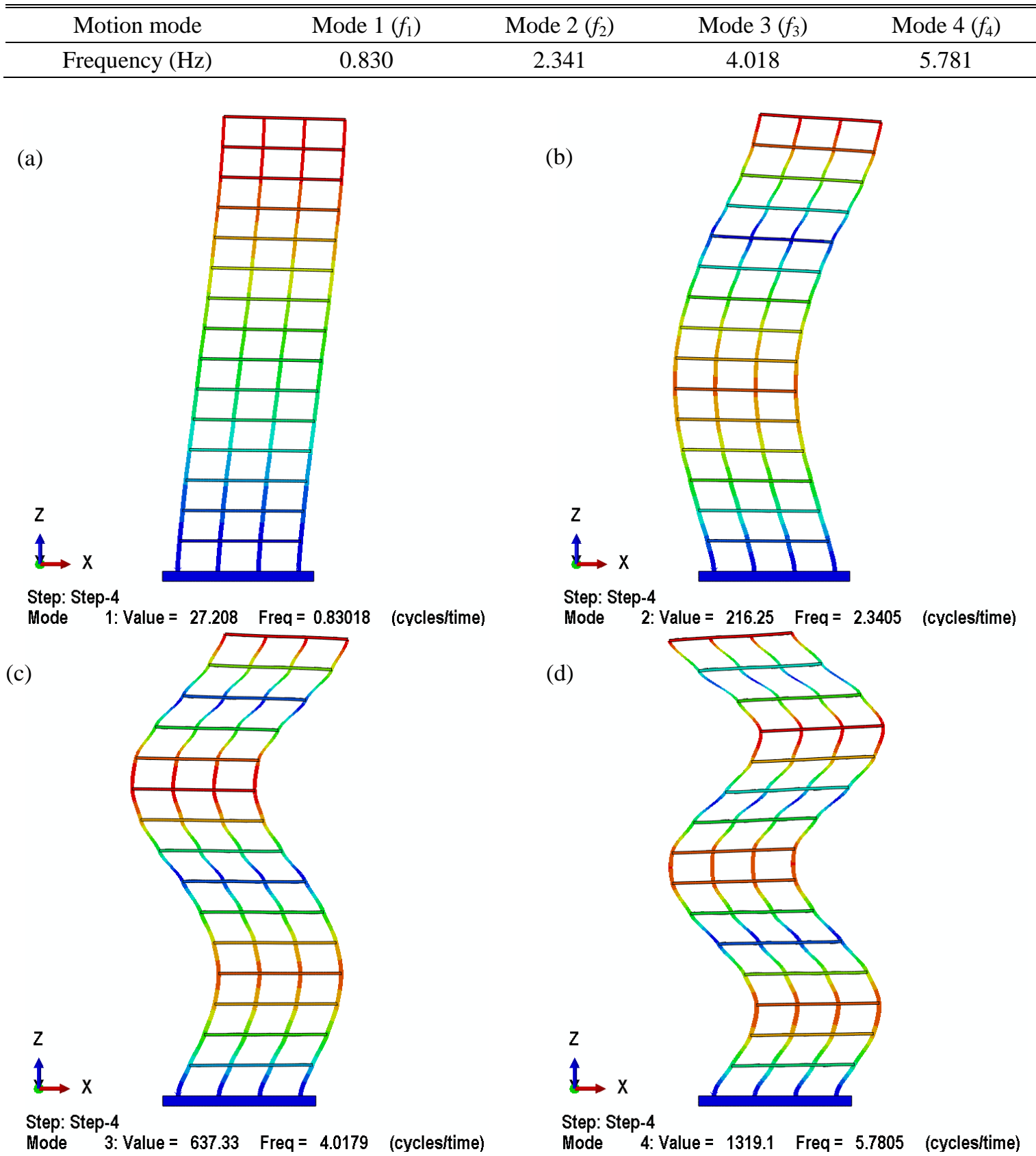

Fig. 10 Representation of structural deformations for fixed base structure (a) first mode, (b) second mode, (c) third mode, and (d) forth mode

The corresponding maximum inter-storey drifts of the building for shallow foundations with different sizes were calculated using the following equation, and based on the Australian standard (AS1170.4 2007) 

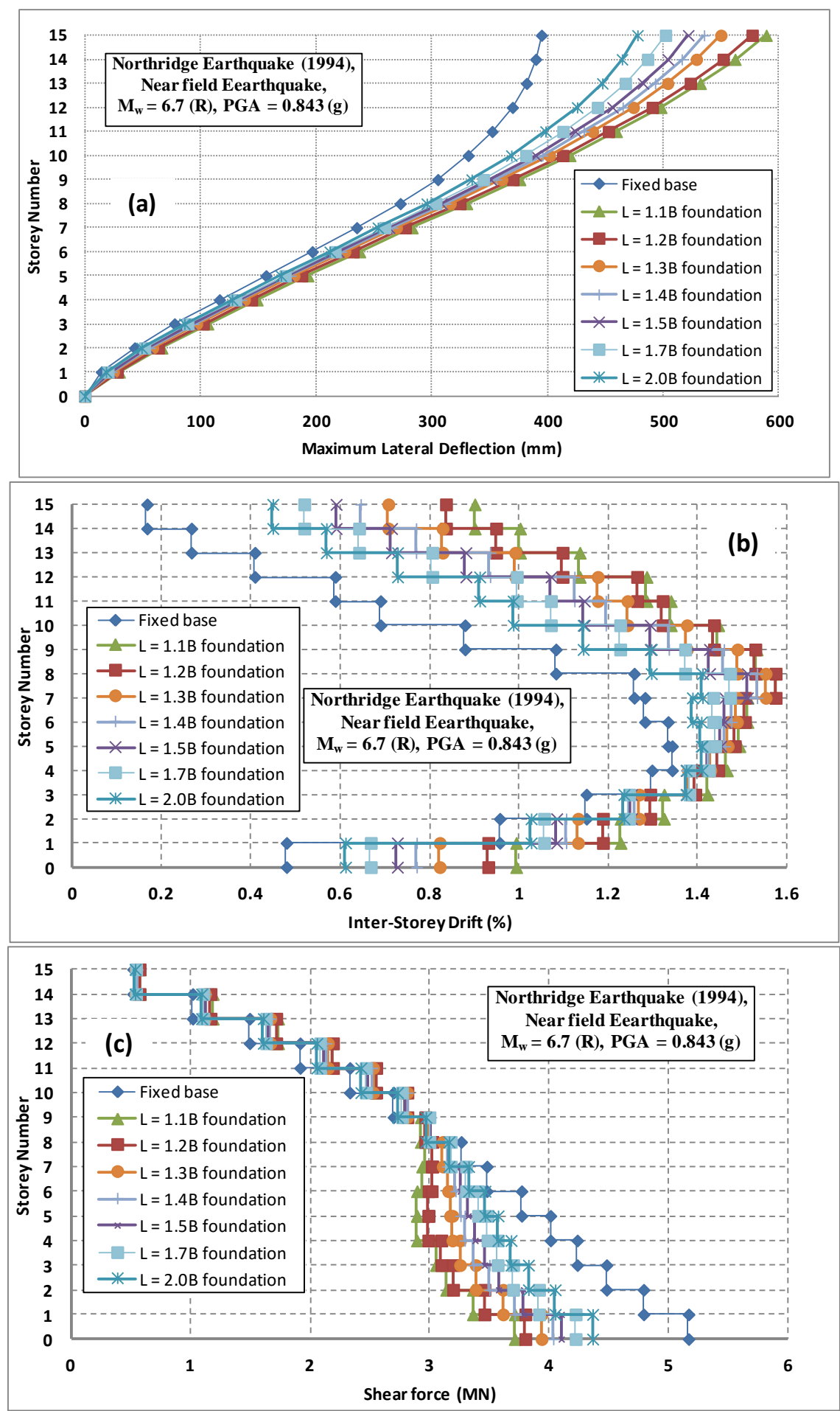

Fig. 11 Response of the fifteen-storey structure supported by shallow foundations with varies sizes under the influence of 1994 Northridge earthquake: (a) maximum lateral deflection; (b) maximum inter-storey drifts; (c) maximum shear force distribution 

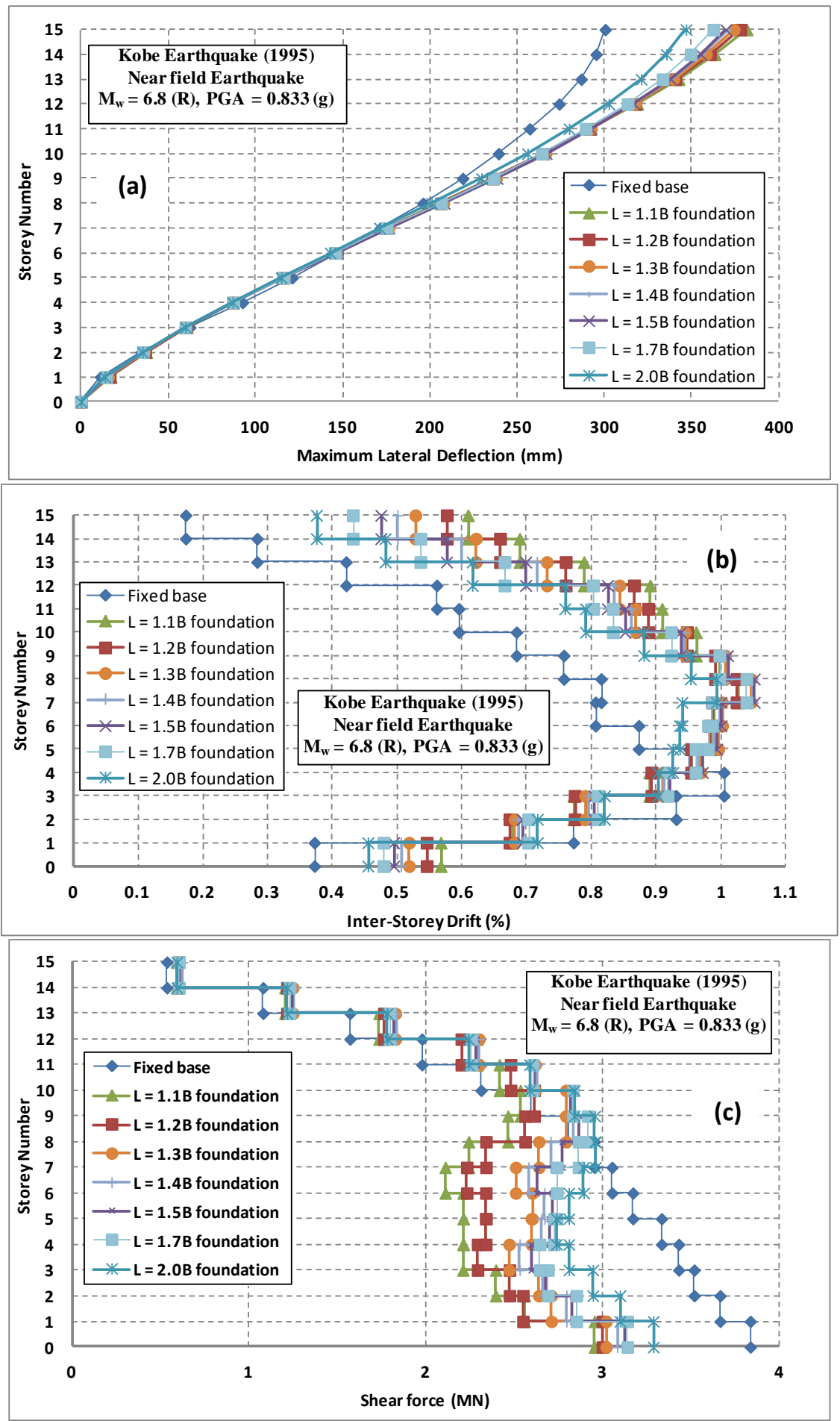

Fig. 12 Response of the fifteen-storey structure supported by shallow foundations with varies sizes under the influence of 1995 Kobe earthquake: (a) maximum lateral deflection; (b) maximum interstorey drifts; (c) maximum shear force distribution 

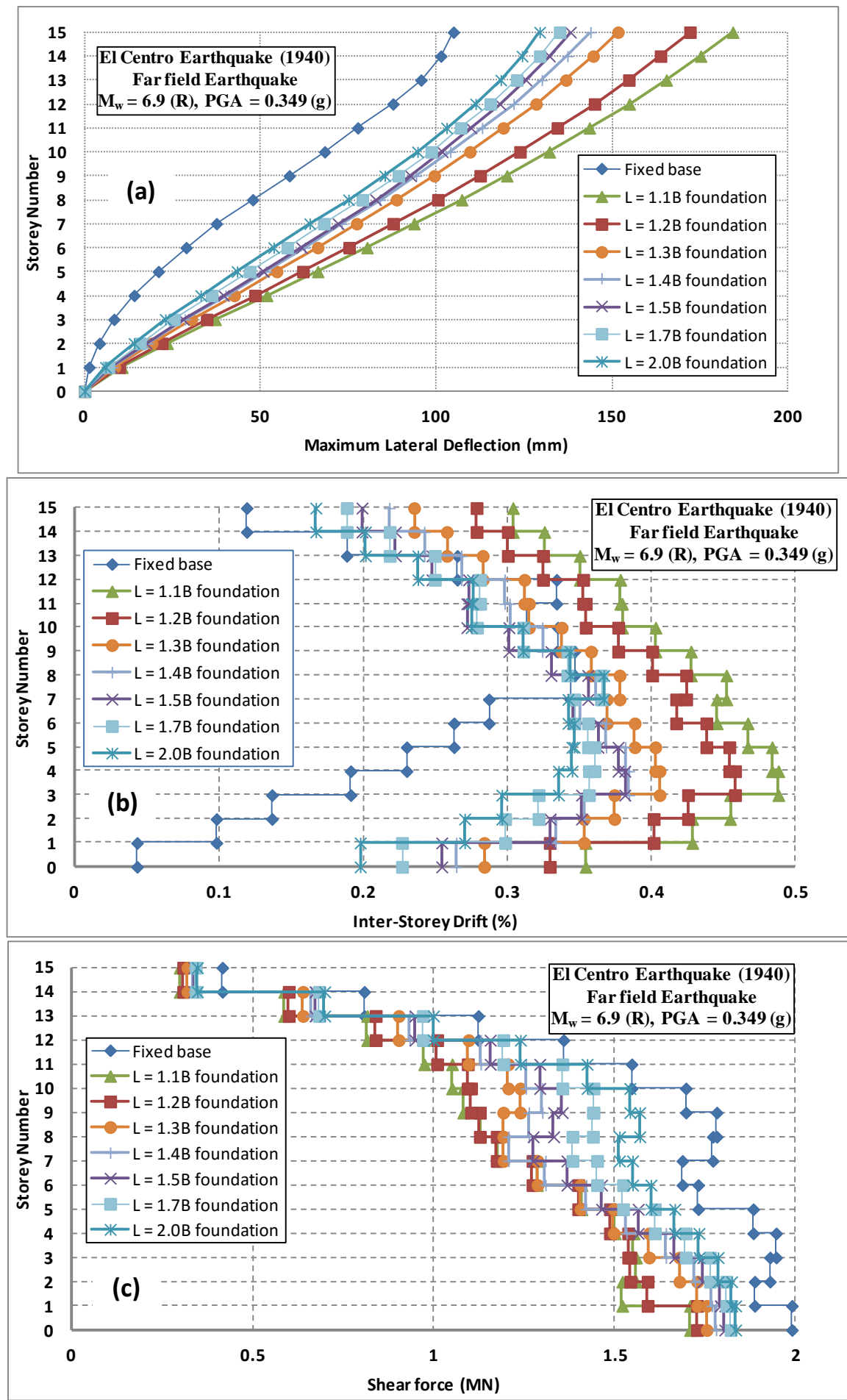

Fig. 13 Response of the fifteen-storey structure supported by shallow foundations with varies sizes under the influence of 1940 El Centro earthquake: (a) maximum lateral deflection; (b) maximum interstorey drifts; (c) maximum shear force distribution 

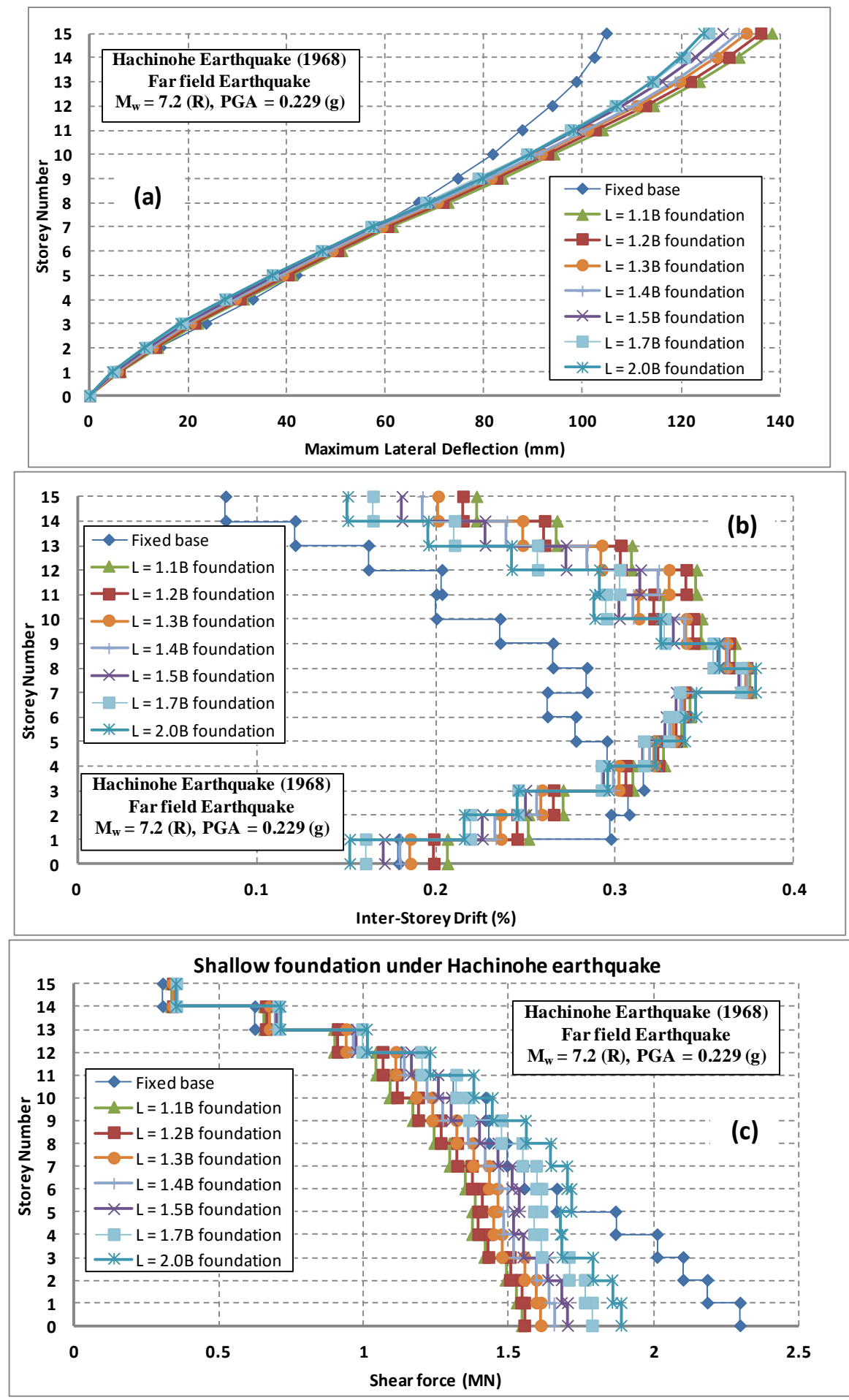

Fig. 14 Response of the fifteen-storey structure supported by shallow foundations with varies sizes under the influence of 1968 Hachinohe earthquake: (a) maximum lateral deflection; (b) maximum inter-storey drifts; (c) maximum shear force distribution 


$$
\text { Drift }=\left(d_{i+1}-d_{i}\right) / h
$$

where $d_{i+1}$ is deflection at $(i+1)$ level, $d_{i}$ is deflection at $(i)$ level, and $h$ is the height of the storey. The seismic performance (performance level) in the performance-based seismic design is described by considering the maximum allowable damage state (damage performance) for an identified seismic hazard (hazard level). The performance levels describe the state of structures after being subjected to a certain hazard level, and based on (BSSC 1997) are classified as: fully operational, operational, life safe, near collapse, or collapse. Overall lateral deflection, ductility demand, and inter-storey drifts are the most commonly used damage parameters. These above mentioned five qualitative levels are related to the corresponding quantitative maximum interstorey drifts (as a damage parameter) of: $<0.2 \%,<0.5 \%,<1.5 \%,<2.5 \%$, and $>2.5 \%$, respectively (BSSC 1997). Moreover, most of the force-based design codes use an additional check in terms of limiting the inter-storey drifts to ensure that particular deformation-based criteria are met. For example, ASCE7-10 (2010) defines allowable storey drift for structures by considering the type and risk category of the structure. The Australian Earthquake Code (AS1170.4 2007) indicates $1.5 \%$ as the maximum allowable storey drift. According to Figs. 11(b), 12(b), 13(b), and 14(b), increasing the size of a shallow foundation reduces the maximum inter-storey drifts experienced by the building. For instance, an increase in the size of the foundation from 1.1B to 1.4B resulted in up to $23 \%$ less inter-storey drift under the 1940 El Centro earthquake. As a result, a larger foundation size is an option that design engineers can use to control the performance level of buildings under shaking loads rather than using larger structural sections.

Fig. 15 presents the time-history rocking response of a fifteen-storey structure supported by shallow foundations of various sizes. Rocking occurs when the inertial forces generated in a superstructure cause compression on one side and tension on the other, which in turn results in settlement on one side and a possible uplift on the other side. The maximum rocking of a fifteenstorey structure supported by shallow foundations of various sizes under the influence of four

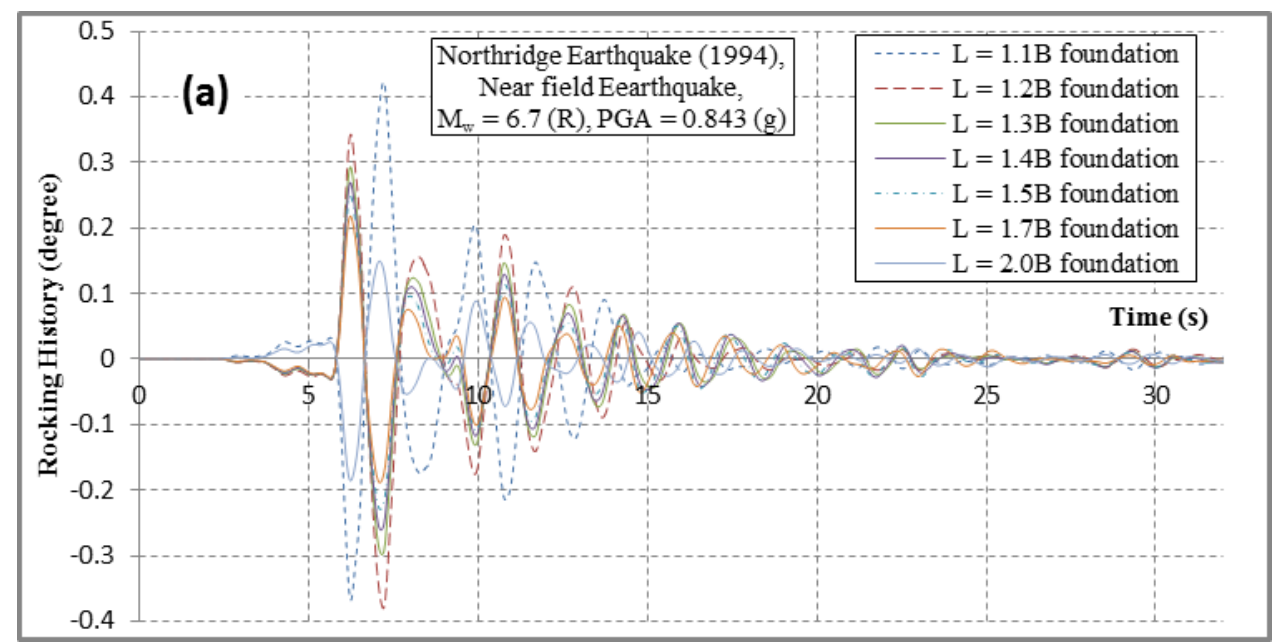

Fig. 15 Time-history rocking response of the fifteen-storey structure supported by shallow foundations with varies sizes under the influence of: (a) 1994 Northridge earthquake; (b) 1995 Kobe; (c) 1940 El Centro earthquake; (d) 1968 Hachinohe earthquake 

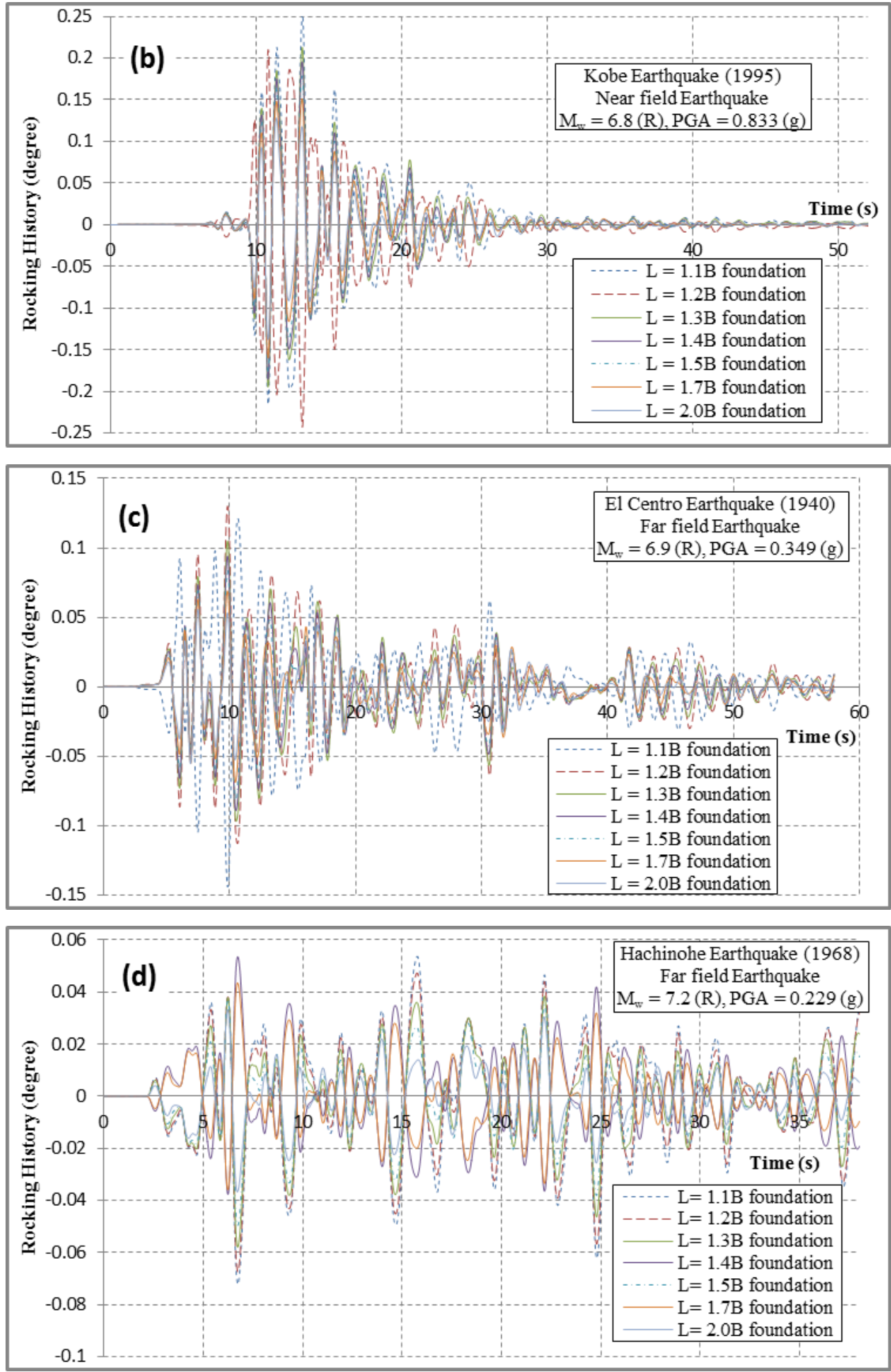

Fig. 15 Continued 

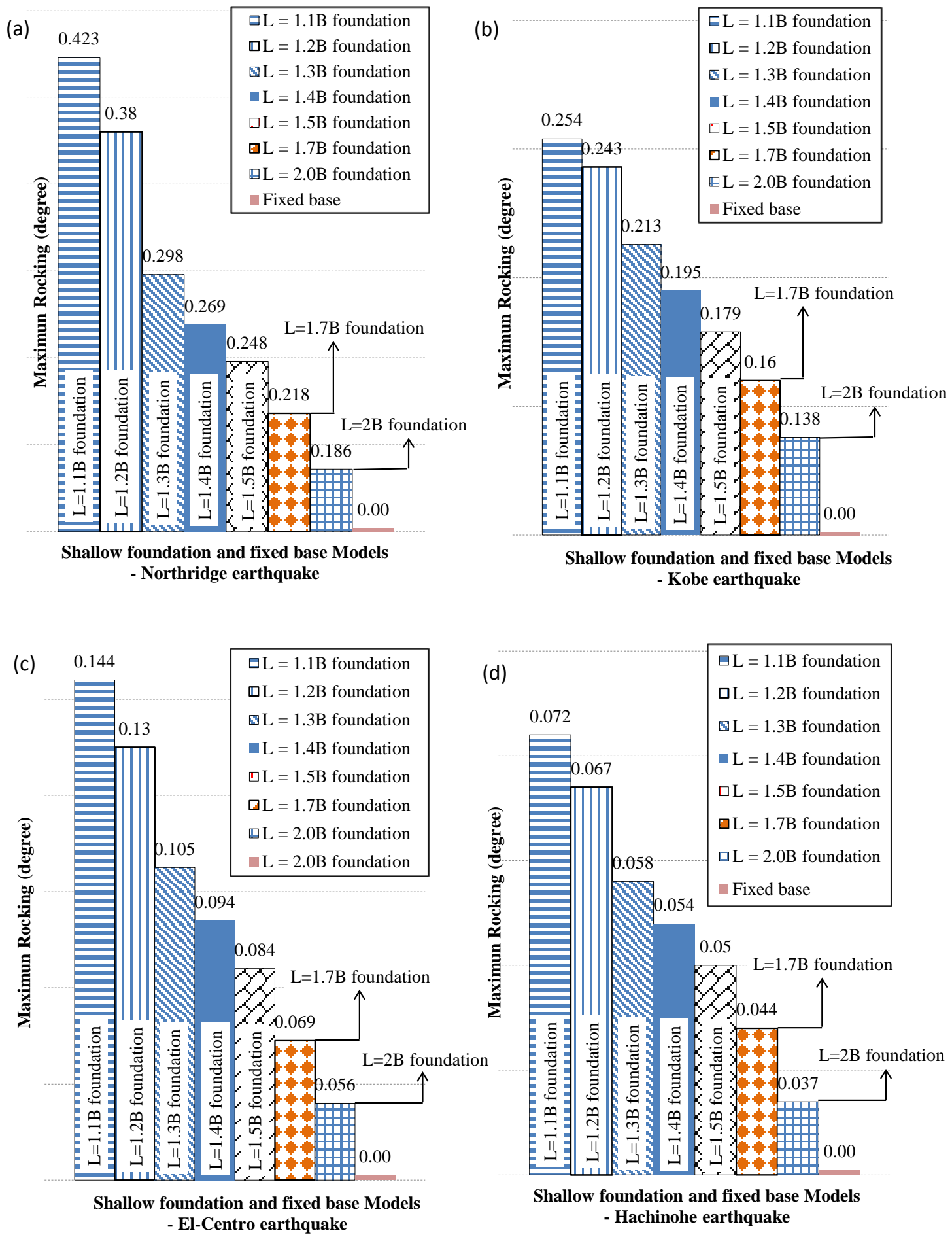

Fig. 16 Maximum rocking of the fifteen-storey structure supported by shallow foundations with varies sizes under the influence of: (a) 1994 Northridge earthquake; (b) 1995 Kobe; (c) 1940 El Centro earthquake; (d) 1968 Hachinohe earthquake 

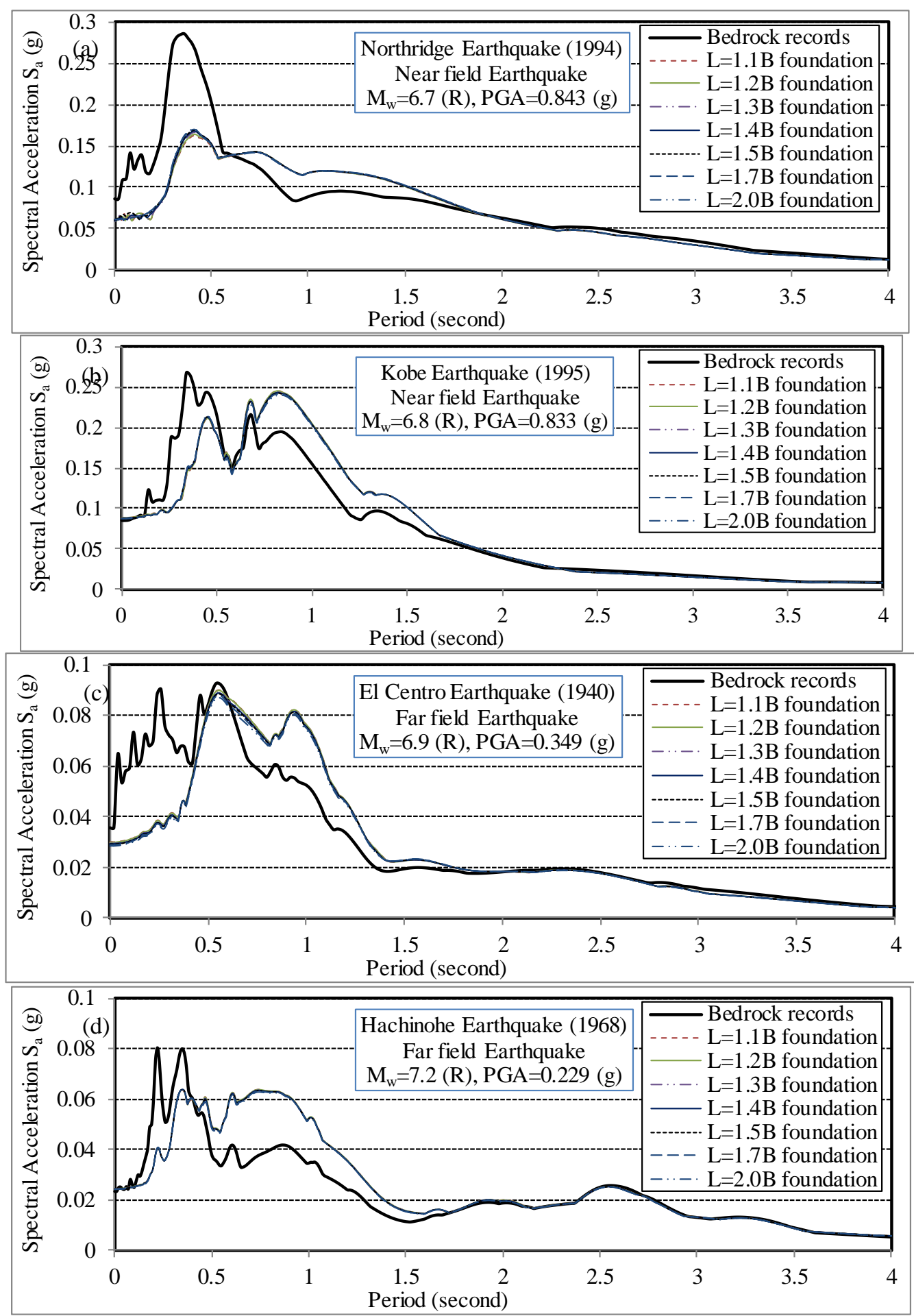

Fig. 17 Acceleration response spectrum with 5\% damping ratio for the structure with different foundation types under the influence of: (a) 1994 Northridge earthquake; (b) 1995 Kobe; (c) 1940 El Centro earthquake; (d) 1968 Hachinohe earthquake 
earthquake excitations is shown in Fig. 16. Accordingly, there was a direct correlation between the size of the shallow foundation and the maximum rocking experienced by a structure, where a superstructure supported by a larger shallow foundation experienced much less rocking than the building supported by a smaller shallow foundation. For instance, the maximum rocking angle of the structure supported by 1.1B foundation under 1940 El Centro earthquake was 0.144 degree, while the corresponding value for the structure supported by $1.5 \mathrm{~B}$ foundation was 0.084 degree (42\% less rocking). How far a structure will rock is the key parameter that directly influences the maximum lateral deflections and inter-storey drifts experienced by the structure during strong earthquakes. Consequently, adopting larger shallow foundations caused less rocking (Fig. 16) which resulted in less lateral deformation (Figs. 11(a)-14(a)) of the structure under shaking excitations.

Fig. 17 illustrates the response spectrum of the ground motions at the base of the structure supported by shallow foundations of various sizes. The response spectrum presents the peak acceleration of a single degree of freedom (SDF) system with 5\% damping, and with different natural periods for the recorded earthquake motions on the ground surface. The size of a shallow foundation may influence the characteristics of earthquake motion at the base of the structure by altering the inertial and kinematic interactions. The inertial force generated by the mass of the structure and the foundation can create more motion at the base than with free field motion (kinematic interaction). On the other hand, as Kramer (1996) explained, the inability of a shallow foundation to match the free field deformation (kinematic interaction) also contributes to the variations in the base motions. Kinematic interaction reduces the foundation motion relative to the free field motion because the stiffness of the foundation and surrounding soil differs, as Veletsos and Prasad (1989) concluded. Referring to Fig. 17, although by increasing the size of a foundation the mass and stiffness of the system increases, the influence of the size of a shallow foundation on the shape of the base response spectrum was insignificant in the cases investigated in this study and can be omitted.

The response spectrums are commonly used to apply the knowledge of structural dynamics to the design of structures and calculate the lateral force requirements (base shears) in building codes as a function of the natural frequency of the system. The size of a shallow foundation alters the natural frequency of the soil-foundation-structure system in comparison to a fixed-base structure, as shown in Table 6. The deformed shapes of the soil-foundation-structure system for the two first natural modes are shown in Fig. 18. For instance, while the first natural frequency of the fixedbase structure in this study was $0.83 \mathrm{~Hz}$, the same structure supported by $1.1 \mathrm{~B}$ and $1.5 \mathrm{~B}$ shallow foundations under the influence of 1994 Northridge earthquake possessed a first mode natural frequency of $0.425 \mathrm{~Hz}$ and $0.462 \mathrm{~Hz}$, respectively. This change in the dynamic characteristics of the system was one of the main contributors to the amount of energy absorbed by a structure subjected to strong earthquakes. For instance, referring to Fig. 17 and Table 6, the fixed-base structure and the structure supported by $1.1 \mathrm{~B}$ and $1.5 \mathrm{~B}$ shallow foundations absorbed different amounts of energy from the imposed earthquake that corresponded to the natural frequencies of each case.

In order to investigate the influence foundation size on the energy absorbed by the structure during earthquakes, the results of the developed 3D numerical model in terms of shear forces were compared for different cases. To determine the maximum shear force at each level, the shear forces generated in every column at that level were summed up in every time increment during the time-history analysis, and the absolute maximum shear force experienced at that level during the earthquake is reported as presented in Figs. 11(c), 12(c), 13(c), and 14(c). In general, considering 
SFSI contributed to the reduction in the shear forces in the structure as expected, whereas larger shallow foundations attracted more inertial forces from the earthquake excitations than the smaller sized foundations. For instance, the maximum base shear of the structure supported by the $1.5 \mathrm{~B}$ foundation under the 1994 Northridge earthquake was 4.1 MN, while the corresponding value for

Table 6 Variations of natural frequencies of soil-structure systems with different foundation size

\begin{tabular}{|c|c|c|c|c|c|c|c|c|c|}
\hline \multirow{2}{*}{\multicolumn{2}{|c|}{$\begin{array}{c}\text { Soil Properties } \\
\text { (Adopted } \\
\text { Earthquake) } \\
\end{array}$}} & \multicolumn{8}{|c|}{ Frequency $(\mathrm{Hz})$} \\
\hline & & \multicolumn{2}{|c|}{$\begin{array}{c}G / G_{\max }=0.25, \\
\xi=15.9 \% \\
\text { (Northridge) }\end{array}$} & \multicolumn{2}{|c|}{$\begin{array}{c}/ G_{\max }=0.3, \\
\xi=14.6 \% \\
(\text { Kobe })\end{array}$} & \multicolumn{2}{|c|}{$\begin{array}{c}G / G_{\max }=0.65 \\
\xi=7.2 \% \\
(\text { Hachinohe) }\end{array}$} & \multicolumn{2}{|c|}{$\begin{array}{c}G / G_{\max }=0.35 \\
\xi=12.8 \% \\
(\text { El-Centro) }\end{array}$} \\
\hline \multicolumn{2}{|c|}{ Motion mode } & $\begin{array}{c}\text { Mode } 1 \\
\left(f_{1}\right)\end{array}$ & $\begin{array}{c}\text { Mode } 2 \\
\left(f_{2}\right)\end{array}$ & $\begin{array}{c}\text { Mode } 1 \\
\left(f_{1}\right)\end{array}$ & $\begin{array}{c}\text { Mode } 2 \\
\left(f_{2}\right)\end{array}$ & $\begin{array}{c}\text { Mode } 1 \\
\left(f_{1}\right)\end{array}$ & $\begin{array}{c}\text { Mode } 2 \\
\left(f_{2}\right)\end{array}$ & $\begin{array}{c}\text { Mode } 1 \\
\left(f_{1}\right)\end{array}$ & $\begin{array}{c}\text { Mode } 2 \\
\left(f_{2}\right)\end{array}$ \\
\hline \multirow{7}{*}{ 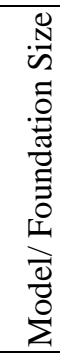 } & $\mathrm{L}=1.1 \mathrm{~B}$ & 0.425 & 2.266 & 0.465 & 2.275 & 0.604 & 2.305 & 0.485 & 2.279 \\
\hline & $\mathrm{L}=1.2 \mathrm{~B}$ & 0.431 & 2.267 & 0.472 & 2.276 & 0.615 & 2.307 & 0.492 & 2.280 \\
\hline & $\mathrm{L}=1.3 \mathrm{~B}$ & 0.443 & 2.271 & 0.486 & 2.280 & 0.637 & 2.311 & 0.508 & 2.284 \\
\hline & $\mathrm{L}=1.4 \mathrm{~B}$ & 0.449 & 2.274 & 0.493 & 2.283 & 0.648 & 2.313 & 0.515 & 2.287 \\
\hline & $\mathrm{L}=1.5 \mathrm{~B}$ & 0.453 & 2.275 & 0.498 & 2.284 & 0.657 & 2.315 & 0.521 & 2.288 \\
\hline & $\mathrm{L}=1.7 \mathrm{~B}$ & 0.457 & 2.279 & 0.505 & 2.288 & 0.673 & 2.320 & 0.529 & 2.293 \\
\hline & $\mathrm{L}=2.0 \mathrm{~B}$ & 0.462 & 2.282 & 0.513 & 2.292 & 0.692 & 2.328 & 0.539 & 2.297 \\
\hline \multicolumn{2}{|c|}{$\begin{array}{l}\text { Fixed base } \\
\text { Structure }\end{array}$} & & & & & & 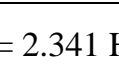 & & \\
\hline
\end{tabular}

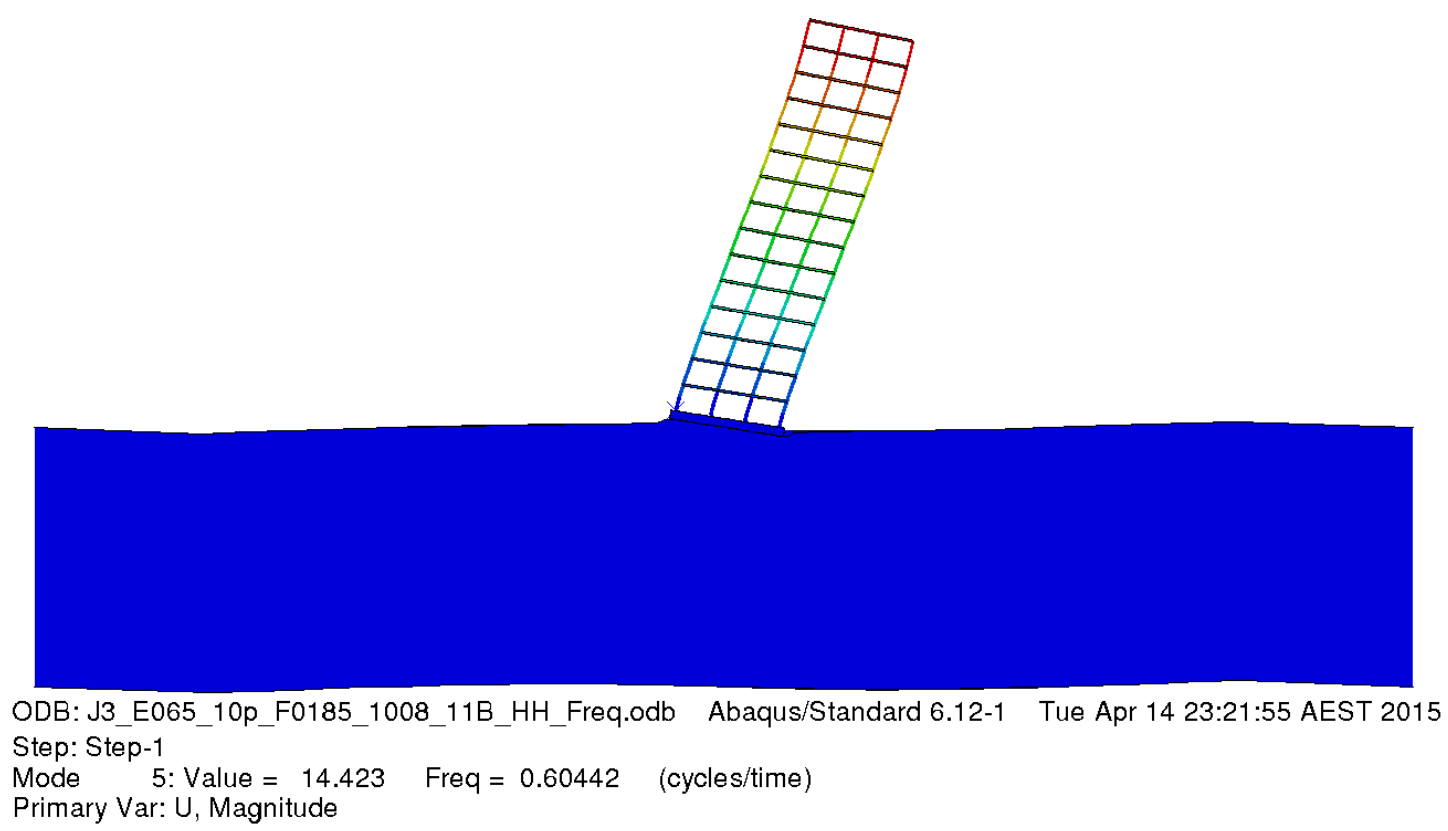

(a)

Fig. 18 Representation of structural deformations considering soil-foundation-structure interaction (a) first mode and (b) second mode 


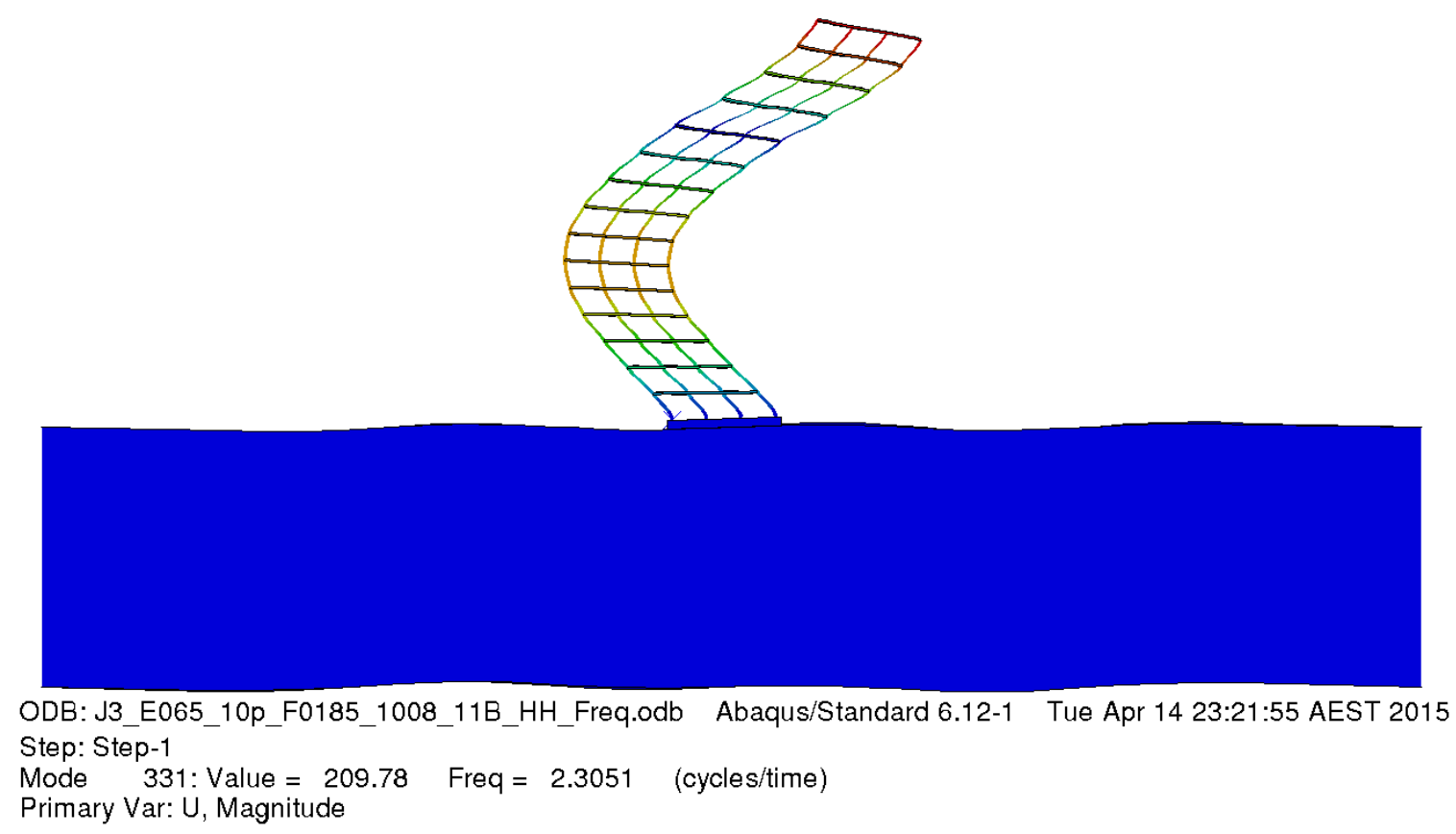

(b)

Fig. 18 Continued

the structure supported by 1.1B foundation was $3.6 \mathrm{MN}$ (13\% less energy absorption). This was due to changes in the dynamic characteristics of the system with various foundations sizes, as discussed earlier.

Decreasing the size of a foundation caused the spectral acceleration to decrease considerably as the natural period lengthened. As a result, such an increase in the natural period substantially changed the response spectral acceleration $\left(S_{a}\right)$. In the case where the mid-rise moment resisting building frames with a shallow foundation rests on soft soil deposits, the natural period lay in the long period region of the acceleration response spectrum curve. Due to the natural period lengthening induced by a reduction in the size of a foundation, the spectral acceleration $\left(S_{a}\right)$ tended to decrease, which then reduced the base shear of the structure.

Consequently, when a design engineer's primary concern is to improve the total stability of a structure by reducing the rocking component, increasing the size of a shallow foundation might be an appropriate option considering the cases investigated in this study. However, in most cases, where the failure of the structural elements is the main safety concern, structures with smaller shallow foundation size attract less shear forces, and thus the level of damage to a structure with smaller foundations would be less, and it is more likely to survive strong earthquakes. It should be noted that the minimum foundation size is determined based on the bearing capacity requirements.

\section{Conclusions}

The aim of this study was to evaluate and quantify the influence of shallow foundation size on 
the seismic response of a regular mid-rise moment resisting building frame during earthquake excitations. In order to achieve this goal, ABAQUS was used to numerically simulate the soilfoundation-structure system by conducting a fully coupled nonlinear time history analysis.

According to the results obtained, the size of a shallow foundation can influence the structural design of the building under seismic loads considering the seismic soil-foundation-structure interaction. Larger shallow foundations can moderate the amplifications of lateral deflection and in turn inter-storey drifts of the structure caused by SFSI. This can be a cost effective alternative to control the performance level of buildings.

The size of a shallow foundation altered the fundamental frequency of the soil-foundationstructure system considerably, whereas its influence on the higher natural modes was insignificant. As a result, changes in the size of shallow foundations resulted in absorbing an amount of energy from the imposed earthquake that corresponded to the natural frequency of a particular system. It was observed that buildings with larger shallow foundations attracted more inertial forces from earthquake excitations than smaller foundations. In other words, the mid-rise moment resisting building frame with shallow foundations on soft soil had a natural period in the long period region of the acceleration response spectrum curve, and because this natural period lengthened, there was a significant reduction in the base shears when the size of the foundation was reduced.

\section{References}

ABAQUS (2012), Abaqus Analysis User's Manual, Minneapolis, Minnesota, Dassault Systèmes Simulia Corp., USA.

ACI318-08 (2008), Building Code Requirements for Structural Concrete and Commentary, American Concrete Institute.

AS1170.4 (2007), Structural design actions-Earthquake actions in Australia, Standards Australia, Australia.

AS2149 (2009), Pilling-Design and installation, Standards Australian, NSW, Australia.

AS3600 2009), Concrete Structures, Standards Australia, NSW, Australia.

ASCE7-10 (2010), Minimum Design Loads for Buildings and Other Structures American Society of Civil Engineers.

ATC-40 (1996), Seismic Evaluation and Retrofit of Concrete Buildings, California Department of Transportation.

Borja, R.I., Wu, W.H., Amies, A.P. and Smith, H.A. (1994), "Nonlinear lateral, rocking and torsional vibration of rigid foundations", J. Geotech. Eng., 120(3), 491-513.

Bowles, J.E. (2001), Foundation Analysis and Design, McGraw-Hill International, Editions, 5th Edition, Civil Engineering Series.

BSSC (1997), NEHRP Guidelines for the Seismic Rehabilitation of Buildings, 1997 Edition, Part 1: Provisions and Part 2: Commentary. Federal Emergency Management Agency.

BSSC (2009), NEHRP Recommended Seismic Provisions for New Buildings and Other Structures, Federal Emergency Management Agency.

Chen, L. (2015), "Dynamic interaction between rigid surface foundations on multi-layered half space", Int. J. Struct. Stab. Dyn., 16, 1550004.

Chopra, A.K. (2007), Dynamics of Structures, Prentice Hall.

Chu, D. and Truman, K.Z. (2004), "Effects of pile foundation configurations in seismic soil-pile-structure interaction", 13th World Conference on Earthquake Engineering, Vancouver, B.C., Canada.

Cohen, M. and Jennings, P.C. (1983), "Silent boundary methods for transient analysis", Eds. Belytschko, T. and Hughes, T.J.R., Computational Methods for Transient Analysis, Elsevier Science Publishers, Amsterdam. 
CSI (2010), SAP2000 v14 Analysis Reference Manual, CSI (Computers and Structures Inc.), Berkley, California.

Das, B.M. (1983), Fundamentals of soil dynamics, Elsevier.

Dutta, S. C. and Roy, R. (2002. A critical review on idealization and modeling for interaction among soilfoundation-structure system. Computers \& Structures, 80, 1579-1594.

Fatahi, B. and Tabatabaiefar, S. (2014), "Fully nonlinear versus equivalent linear computation method for seismic analysis of mid-rise buildings on soft soils", Int. J. Geomech., 14, doi:10.1061/(ASCE)GM.19435622.0000354 .

Fatahi, B., Tabatabaiefar, S. and Samali, B. (2014), "Soil-structure interaction vs Site effect for seismic design of tall buildings on soft soil”, Geomech. Eng., 16, 293-320.

Gazetas, G. and Mylonakis, G. (1998), "Seismic soil-structure interaction: new evidence and emerging issues", Proc. 3rd Conf. Geotechnical Earthquake Engineering and Soil Dynamics, Seattle, USA.

Hokmabadi, A.S., Fatahi, B. and Samali, B. (2012), "Recording inter-storey drifts of structures in timehistory approach for seismic design of building frames", Aust. J. Struct. Eng., 13, 175-179.

Hokmabadi, A.S. and Fatahi, B. (2015), "Influence of foundation type on seismic performance of buildings considering soil-structure interaction”, Int. J. Struct. Stab. Dyn., DOI: 10.1142/S0219455415500431.

Hokmabadi, A.S., Fatahi, B. and Samali, B. (2014), "Assessment of soil-pile-structure interaction influencing seismic response of mid-rise buildings sitting on floating pile foundations", Comput. Geotech., 55, 172-186.

Koskinen, M. (2005), "Modeling of soil-structure interaction between railway bridge and soil", ABAQUS Users' Conference, Stockholm, Sweden.

Kramer, S.L. (1996), Geotechnical earthquake engineering, Prentice Hall.

Kramer, S.L. and Stewart, J.P. (2004), "Geotechnical aspects of seismic hazards", Eds. Bozorgnia, Y. and Bertero, V.V., Earthquake Engineering: From Engineering Seismology to Performance-Based Engineering, CRC Press.

Ma, X.H., Cheng, Y.M., Au, S.K., Cai, Y.Q. and Xu, C.J. (2009), "Rocking vibration of a rigid strip footing on saturated soil", Comput. Geotech., 36, 928-933.

Matinmanesh, H. and Asheghabadi, M.S. (2011), "Seismic analysis on soil-structure interaction of buildings over sandy soil", Procedia Eng., 14, 1713-1743.

Meymand, P.J. (1998), "Shaking table scale model tests of nonlinear soil-pile-superstructure in soft clay", $\mathrm{PhD}$ Thesis in Civil Engineering, University of California, Berkley.

Moss, R.E., Crosariol, V. and Kuo, S. (2010), "Shake table testing to quantify seismic soil structure interaction of underground structures", International Conference on Recent Advances in Geotechnical Earthquake Engineering and Soil Dynamics, San Diego.

Nguyen, D.D.C., Jo, S.B. and Kim, D.S. (2013), "Design method of piled-raft foundations under vertical load considering interaction effects", Comput. Geotech., 47, 16-27.

Park, D. and Hashash, Y.M.A. (2004), "Soil damping formulation in nonlinear time domain site response analysis", J. Earthq. Eng., 8, 249-274.

PEER (2012), PEER Ground Motion Database, Pacific Earthquake Engineering Research Centre. University of California, Berkeley, CA.

Poulos, H. and Davis, E. (1980), Pile Foundation Analysis and Design, John Wiley and Sons.

Rahvar (2006), Geotechnical investogation and foundation design report of Mahshahr train station, P.O. Rahvar Pty Ltd, Iran Railway Authority, Mahshar, Iran.

Ryan, K.L. and Polanco, J. (2008), "Problems with Rayleigh damping in base-isolated buildings", J. Struct. Eng., 134, 1780-1784.

Sameti, A.R. and Ghannad, M.A. (2014), "Equivalent linear model for existing soil-structure systems", Int. J. Struct. Stab. Dyn., 16, 1450099.

Sbartai, B. (2015), "Dynamic interaction of two adjacent foundations embedded in a viscoelastic soil", Int. J. Struct. Stab. Dyn., 16, 1450110.

Seed, H.B. and Idriss, I. (1969), "Influence of soil conditions on ground motion during earthquakes", J. Soil Mech. Found. Div., ASCE, 95, 99-137. 
Shing, B.P. and Tanabe, T. (2001), Modeling of inelastic behavior of RC structures under seismic loads, American Society of Civil Engineers (ASCE), Reston, VA.

Stewart, J., Fenves, G. and Seed, R. (1999), "Seismic soil-structure interaction in buildings. I: Analytical aspects", J. Geotech. Geoenv. Eng., 125, 26-37.

Tabatabaiefar, H.R., Fatahi, B. and Samali, B. (2013), "Seismic behavior of building frames considering dynamic soil-structure interaction", Int. J. Geomech., 13, 409-420.

Tabatabaiefar, S., Fatahi, B. and Samali, B. (2014a), "An empirical relationship to determine lateral seismic response of mid-rise building frames under influence of soil-structure interaction", Struct. Des. Tall Spec. Build., 23, 526-548.

Tabatabaiefar, S. and Fatahi, B. (2014), "Idealisation of soil-structure system to determine inelastic seismic response of mid-rise building frames", Soil Dyn. Earthq. Eng., 66, 339-351.

Tabatabaiefar, S., Fatahi, B. and Samali, B. (2014b), "Numerical and experimental investigations on seismic response of building frames under influence of soil-structure interaction", Adv. Struct. Eng., 17, 109-130.

Veletsos, A. and Prasad, A. (1989), "Seismic interaction of structures and soils: stochastic approach", $J$. Struct. Eng., 115, 935-956.

Veletsos, A.S. and Meek, J.W. (1974), "Dynamic behaviour of building-foundation systems", Earthq. Eng. Struct. Dyn., 3, 121-138.

Vucetic, M. and Dobry, R. (1991), "Effect of soil plasticity on cyclic response", J. Geotech. Eng., 117, 89107.

Wolf, J. (1998), Soil-Structure Interaction Analysis in Time Domain, Prentice Hall Co, New Jersey. 